\title{
Experimental study on the working performance of different milling tools for multistage fracturing ball seats
}

\author{
Jia-Qi Che ${ }^{1} \cdot$ Han-Xiang Wang ${ }^{1} \cdot$ Yan-Wen Zhang ${ }^{1} \cdot$ Ming-Chao Du ${ }^{1} \cdot$ Shao-Hua Ma ${ }^{1}$
}

Received: 7 February 2020 / Published online: 28 August 2020

(c) The Author(s) 2020

\begin{abstract}
To achieve the secondary production in multistage fracturing wells of tight oil, milling tools are usually used to remove the multistage fracturing ball seats to achieve production with a large diameter in later. In this paper, first of all, the working mechanism of milling tools for multistage fracturing ball seats was studied and a mechanical analysis model of single abrasive grain was established. Then, an experimental system for milling tools was developed, and the experimental tests of the flat, the blade, and the slope milling tool were conducted in order. Besides, the morphology of chips and the surface morphology of the workpiece after the experiment were analyzed. Also, the working performance of milling tools was evaluated from the perspectives of working safety, working efficiency, and wear resistance of the milling tool. The results show that the torque of the milling tool increases nonlinearly with the increase in the cutting depth of the abrasive grain and increases linearly with the increase in the cutting width. Also, the chips are irregular particles and the size is mainly from 10 to $50 \mu \mathrm{m}$. So, the chips should be pumped up with a small pump pressure and a large displacement. Besides this, the cutting depths of the abrasive grains are from 216.20 to $635.47 \mu \mathrm{m}$ and the bottom surface of the milling tool should be eccentric to avoid the zero point of cutting speed. Furthermore, the torque of the slope milling tool is $23.8 \%$ larger than that of the flat milling tool, which is also $30.4 \%$ smaller than that of the blade milling tool. Compared with the flat milling tool, the working efficiency of the blade milling tool improves by $79.9 \%$ and the slope milling tool improves by $111.1 \%$. Also, the wear resistance of the blade milling tool decreases by $102.7 \%$, while the slope milling tool declines by $32.6 \%$ when compared with the flat milling tool. Therefore, the slope milling tool has the characteristics of moderate torque, stable working conditions, the highest working efficiency, and fine wear resistance, which is preferably used to mill multistage fracturing ball seats. This study provides a theoretical basis and guidance for milling multistage fracturing ball seats on-site and realizing production with a large diameter in later stages of multistage fracturing wells.
\end{abstract}

Keywords Multistage fracturing ball seat $\cdot$ Milling tool $\cdot$ Working performance $\cdot$ Tight oil $\cdot$ Experimental system $\cdot$ Single abrasive grain

\section{Introduction}

With the rapid development in exploration technology, unconventional oil and gas resources, such as tight gas, tight oil, and shale oil, have been successfully developed all over the world (Zhang et al. 2016; Zhao and Hou 2017; Li et al.

\section{Edited by Xiu-Qiu Peng}

\section{Han-Xiang Wang \\ wanghxupc@163.com}

1 College of Mechanical and Electronic Engineering, China University of Petroleum (East China), Qingdao 266580, Shandong, People's Republic of China 2019a, b; Qu et al. 2019). As a typical kind of unconventional resources, tight oil has recently taken on great significance in global hydrocarbon exploration, which is also seen as the major force to replace conventional resources and support energy revolution (Zhao et al. 2017; Cai et al. 2019; Longde et al. 2019; Sun et al. 2019). To be more specific, tight oil refers to the oil preserved in tight sandstone or tight carbonate rocks with overburden pressure matrix permeability less than or equal to $0.1 \times 10^{-3} \mu \mathrm{m}^{2}$ (Zou et al. 2015). And multistage fracturing technology has been recognized as the main stimulation technology for the development of tight oil (Zhang et al. 2015; Hu et al. 2017), which is also helpful to create or extend many complex fracture networks along a long wellbore (Li et al. 2017; Cheng et al. 2019a, b). So, 
the successful application of multistage fracturing technology has boosted oil production and improved exploitation economics from tight oil obviously in the last decade (Wang et al. 2018; Li et al. 2019a, b).

As one of the most crucial multistage fracturing technologies, the ball and seat multistage fracturing technology has significantly contributed to the development of tight oil (Zheng et al. 2016a, b). The multistage fracturing ball seat, which is utilized to seal the ball, is the key component in multistage fracturing systems (Liu et al. 2020). In order to achieve the secondary production of multistage fracturing wells, the multistage fracturing ball seat should be milled clean by milling tools to remove wellbore blockages and form wellbore with a large diameter. As shown in Fig. 1, force $F$, known as the weight on bit (WOB), and torque $T$ are applied to the milling tool firstly, and then the milling tool starts to rotate under a certain pressure. Due to the large number of cemented carbide grains arranged on the bottom of the milling tool by welding, the fracturing ball and fracturing ball seat would be milled clean by the milling tool. As the material of the ball seat is usually very hard to withstand the erosion of fracturing fluid, it is difficult to mill it out efficiently and safely (Zheng et al. 2015, 2016c). In order to select the milling tool that is more suitable for milling multistage fracturing ball seat, it is important to evaluate the working performance of different milling tools.

As for the analysis and evaluation of milling and drilling tools, in the previous studies, experts and scholars in related fields have carried out a lot of research. Ajibose et al. (2015) studied drillbit-rock interaction via conical and spherical indentation of rocks. Lundberg determined the optimal incident wave shape maximizing the efficiency of wave energy conversion to work at a drill bit (Lundberg and Collet 2015). Kivade et al. (2015) carried out detailed studies to determine the influence of rock properties on the penetration rate

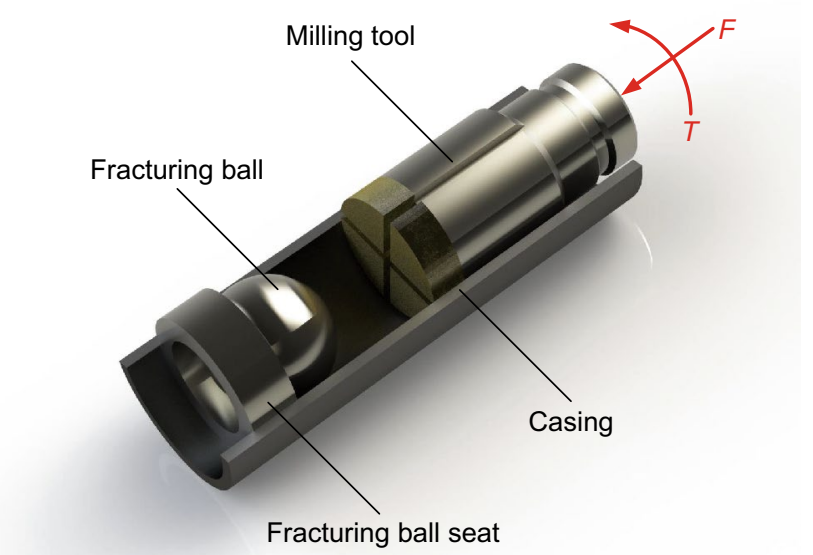

Fig. 1 Milling process of multistage fracturing ball seat during pneumatic drilling. Hashiba et al. 2015 investigated the impact penetration behavior of the button bit in laboratory tests and developed an impact penetration tester built from the same components. Miyazaki et al. (2016) performed percussion drilling tests on hard and highly abrasive granite in a laboratory using PDC and WC-Co percussion bits to evaluate their drilling performance. Munoz et al. (2016) carried out a series of cutting tests using a single PDC cutter at three different back-rake angles and uniaxial compressive tests on different rock types to quantify the intrinsic specific energy and strain energy. Che et al. (2016) formulated a cutting theory to analytically explain how rock interacts with PDC cutters in a simple cutting configuration-linear cutting and conducted comprehensive linear rock cutting tests on a newly developed rock cutting facility. Che et al. (2017) presented an experimental study of the cutter's cutting performance and the rock's failure behaviors on a newly developed linear rock cutting facility to investigate the influences of process parameters and the rock's mechanical properties on chip formation and force responses. Rostamsowlat (2018) carried out an extensive and comprehensive set of cutting experiments on two sedimentary rocks using a state-of-the-art rock cutting equipment and various blunt cutters. Shi et al. (2018) proposed a new drilling method called coiled tubing partial underbalanced drilling (CTPUBD) and presented predictions of hole cleaning efficiency, drilling speed, cuttings migration, and pressure loss in the drilling process based on numerical simulation and full-scale experimental studies. Peng et al. (2019) carried out the experimental study of drilling basalt with small-diameter cemented carbide triangular bit and diamond trepanning drill and established the drilling thrust force models of basalt drilled by cemented carbide triangular bit and diamond trepanning drill, respectively. Zhang et al. (2019) used the finite element to simulate the thermal-structural coupling of the rock breaking process of the full-sized PDC bits and verified the accuracy of the simulation analysis method by experiment. Chen et al. (2019a, b) studied the integrated effect of double cutters on cutting rock and built a cutting model to study the integrated effect of double cutters. Cheng et al. $(2019 a, b)$ proposed a new analytical model of rock cutting force and failure surface based on the stress state calculation of each micro-unit inside the rock. Chen et al. (2019a, b) studied the influence of poroelastic effects on MSE during the rock cutting process and conducted cutting tests on Torrey Buff sandstone and Carthage marble to verify the poroelastic effects in cutting process. In summary, at present, researchers mainly analyze the process of cutting rock to complete the analysis and evaluation of the drill bit. The lack of analysis about the working performance of milling tools for multistage fracturing ball seats has led to the fact that the working performance of different milling tools is not clear now. At the same time, the lack of experimental equipment 
for the study of milling tools for multistage fracturing ball seats makes it impossible to conduct experimental analysis.

In this paper, first of all, the mechanism analysis of the working process for cutting the metallic material of multistage fracturing ball seats by carbide abrasive grains on the milling tool was conducted, and then the experimental equipment for different milling tools was developed. Besides, efficiency, safety, and wear resistance evaluation of different milling tools were carried out. At the same time, the surface morphology and chip morphology after the experiment were analyzed. The experimental study on the working performance of different milling tools for multistage fracturing ball seat provides theoretical guidance for field construction, which is of great significance for removing wellbore blockages and achieving more production at the later stage of multistage fracturing wells.

\section{Analysis of mechanical model}

\subsection{Model assumption}

The process of milling multistage fracturing ball seats by milling tools is essentially a process of cutting and removing the material of multistage fracturing ball seats by the abrasive grains at the bottom of the milling tool. According to the working process of milling ball seats, a mechanical analysis model of single abrasive grain was established. Before the analysis, the following assumptions needed to be made.

(1) The material is homogeneous.

(2) The shear plane develops along the shear angle $\varphi$ to the free plane.

(3) The normal stress and shear stress are evenly distributed.
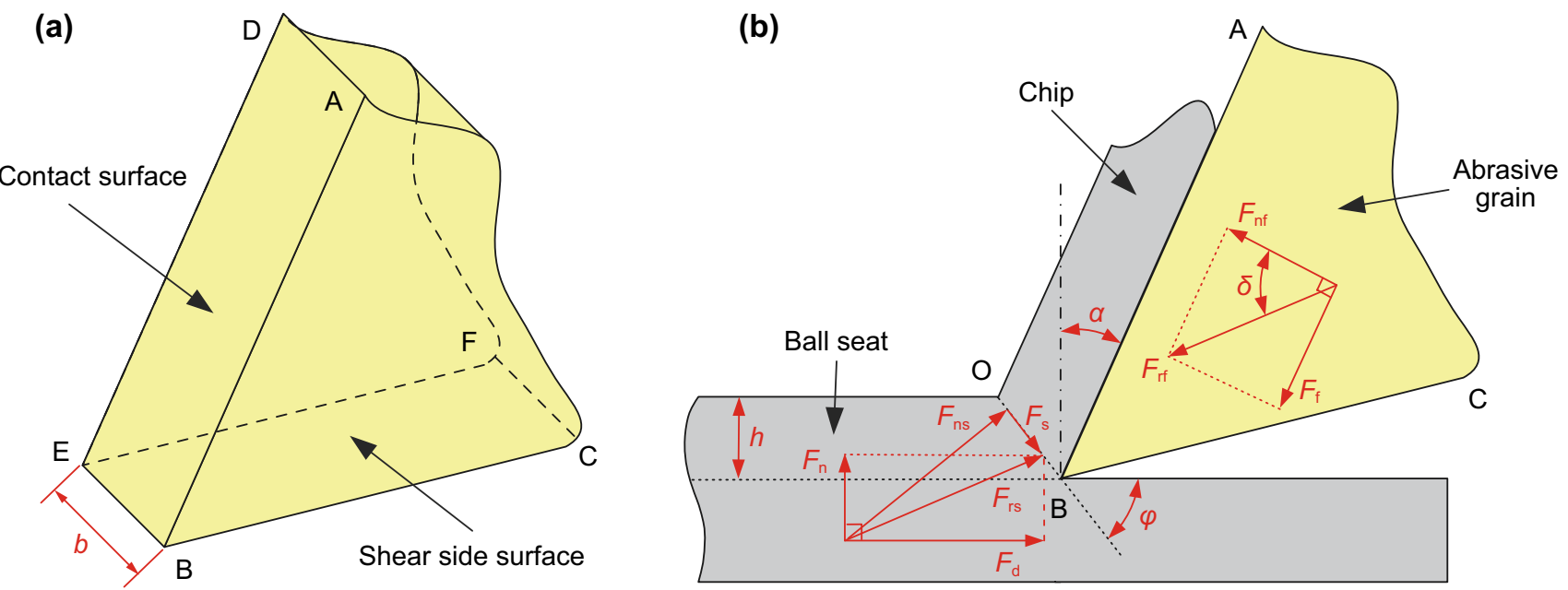

(4) Ignore the wear and passivation effects of abrasive grains.

(5) Ignore the effects of string oscillation.

\subsection{Solution of mechanical model}

The material of multistage fracturing ball seats undergoes cutting deformation in a sliding manner under the extrusion of abrasive grains. With the cutting progress of abrasive grain, a cutting layer will form on the upper surface of the multistage fracturing ball seat. When the shear stress $\tau$ generated by abrasive grains is greater than the critical shear stress $\tau_{s}$ of ball seats, the material on the ball seat will be cut off by abrasive grains. During the cutting process, the resistance to the abrasive grains mainly includes the resistance caused by elastic and plastic deformation of the ball seat and the friction force of the contact section (Sun et al. 2018). According to the model assumption, the process of cutting the material of ball seats by abrasive grains was simplified. The mechanical analysis model of single abrasive grain is shown in Fig. 2.

The positive force $F_{\mathrm{ns}}$ and shear force $F_{\mathrm{s}}$ are on the shear plane $\mathrm{OB}$, and their resultant force is $F_{\mathrm{rs}} . \mathrm{ABC}$ and $\mathrm{DEF}$ are the two shear side surfaces of the cutting layer, and the shearing force on the shear side surfaces $A B C$ and DEF is $F_{\mathrm{ss}}$. ABED is the contact surface between the chips and the abrasive grains. The normal force $F_{\mathrm{nf}}$ and friction force $F_{\mathrm{f}}$ are applied to the contact surface ABED, and their resultant force is $F_{\mathrm{rf}}$.

According to the force balance formula, formula (1) can be derived.

Fig. 2 Mechanical analysis model of single abrasive grain 


$$
\left\{\begin{array}{r}
F_{\mathrm{s}}-F_{\mathrm{rs}} \cos \Phi=0 \\
F_{\mathrm{ns}}-F_{\mathrm{rs}} \sin \Phi=0 \\
F_{\mathrm{rs}}+F_{\mathrm{rf}}=0
\end{array}\right.
$$

where $\Phi=\varphi+\delta-\alpha, \alpha$ is the front angle of abrasive grains, $\varphi$ is the shear angle, and $\delta$ is the friction angle between the abrasive grain and the ball seat. And the shear force $F_{\mathrm{s}}$ on the shear plane OB can be obtained by formula (2).

$F_{\mathrm{s}}=\frac{b h \tau_{\mathrm{s}}}{\sin \varphi}$

where $h$ is the cutting depth, $b$ is the width of abrasive grain, and $\tau_{\mathrm{s}}$ is the critical shear stress of the ball seat.

From formulas (1) and (2), the resultant force $F_{\mathrm{rs}}$ on the contact surface ABED and the normal force $F_{\mathrm{ns}}$ on the shear surface OB can be obtained, respectively, by formula (3).

$\left\{\begin{array}{l}F_{\mathrm{rs}}=\frac{b h \tau_{\mathrm{s}}}{\cos \phi \sin \varphi} \\ F_{\mathrm{ns}}=\frac{b h \tau_{\mathrm{s}} \sin \varphi}{\cos \Phi \sin \varphi}\end{array}\right.$

The resultant force $F_{\mathrm{rs}}$ on the contact surface ABED can be projected along the normal direction of the cutting plane and the direction of the cutting speed, and the normal force $F_{\mathrm{n}}$ as well as the cutting force $F_{\mathrm{d}}$ of the cutting plane can be obtained, respectively, by formula (4).

$\left\{\begin{array}{l}F_{\mathrm{n}}=\frac{b h \tau_{\mathrm{s}} \sin (\delta-\alpha)}{\cos \Phi \sin \varphi} \\ F_{\mathrm{d}}=\frac{b h \tau_{\mathrm{s}} \cos (\delta-\alpha)}{\cos \Phi \sin \varphi}\end{array}\right.$

In addition, the shearing force $F_{\mathrm{ss}}$ on the shear side surfaces $\mathrm{ABC}$ and $\mathrm{DEF}$ can be obtained by formula (5).

$F_{\mathrm{ss}}=\frac{\tau_{\mathrm{s}} h^{2}}{\tan \varphi}$

By formulas (3), (4) and (5), the normal force $F_{\text {nt }}$ and the main cutting force $F_{\mathrm{dt}}$ of the single abrasive grain are obtained by formula (6), respectively.

$\left\{\begin{array}{l}F_{\mathrm{nt}}=\frac{b h \tau_{\mathrm{s}} \sin (\delta-\alpha)}{\cos \Phi \sin \varphi} \\ F_{\mathrm{dt}}=\frac{b h \tau_{\mathrm{s}} \cos (\delta-\alpha)}{\cos \Phi \sin \varphi}+\frac{\tau_{\mathrm{s}} h^{2}}{\tan \varphi}\end{array}\right.$

As the abrasive grain on the milling tool performs a circular cutting motion, the annular diameter is defined as $d$, and the torque $M$ generated by the abrasive grain can be obtained by formula (7).

$M=\frac{d}{2}\left[\frac{b h \tau_{\mathrm{s}} \cos (\delta-\alpha)}{\cos (\varphi+\delta-\alpha) \sin \varphi}+\frac{\tau_{\mathrm{s}} h^{2}}{\tan \varphi}\right]$

It can be known from formula (7) that the torque of the milling tool increases nonlinearly with the increase in cutting depth $h$ of the abrasive grain and increases linearly with the increase in cutting width $b$. Furthermore, the change of front angle $\alpha$ of the abrasive grain leads to periodic fluctuations.

\section{Experimental analysis}

\subsection{Experimental equipment}

\section{(1) Experimental system for milling tools}

Due to the lack of an experimental system for testing the working performance of different milling tools for multistage fracturing ball seats, so an experimental system for milling tools has been developed according to the actual operating conditions of the construction site. The experimental system can test the performance of the milling tools at different speeds and WOB to complete the evaluation of the working efficiency and safety of different milling tools. The experimental system for milling tools is shown in Fig. 3. This system is mainly composed of a milling tool experimental bench, a frequency conversion module, a thrust control module, and a data acquisition module. The milling tool experimental bench mainly includes a power module, a transmission module, and a milling module. The power module includes a variable frequency motor, which mainly provides power for the milling tool. The rotating speed of the variable frequency motor is controlled by the inverter in the frequency conversion module, and the milling tool is driven to rotate by the transmission module. The transmission module includes a reducer and a coupling. The reducer converts the high rotating speed of the motor into low rotating speed and increases the torque. The milling module is equipped with the NC26 threaded joint, which can be connected with different milling tools. Below the milling tool is a four-jaw chuck fixture, which is used to clamp multistage fracturing ball seats or workpieces of the same material. Below the milling module is an electric cylinder. The thrust control module can produce thrusts of different values and apply them to the bottom of the milling tool through the four-jaw chuck fixture to simulate the impact of different WOB on the working performance of milling tools. In addition, the upper end of the electric cylinder is equipped with a pressure sensor, which can measure the pressure at the upper end of the electric cylinder and adjust it through the feedback of the PLC controller to control the output thrust within the set value. Specifically, the adjustable range of output thrust is $0-20 \mathrm{kN}$, the adjustable range of output speed is $0-50 \mathrm{~mm} / \mathrm{s}$ and the adjustment stroke is $200 \mathrm{~mm}$. The error between the output value, such as the speed and the force, and the set value is within $1 \%$. The data acquisition module includes a torque sensor, rotating speed sensor, pressure sensor, and 


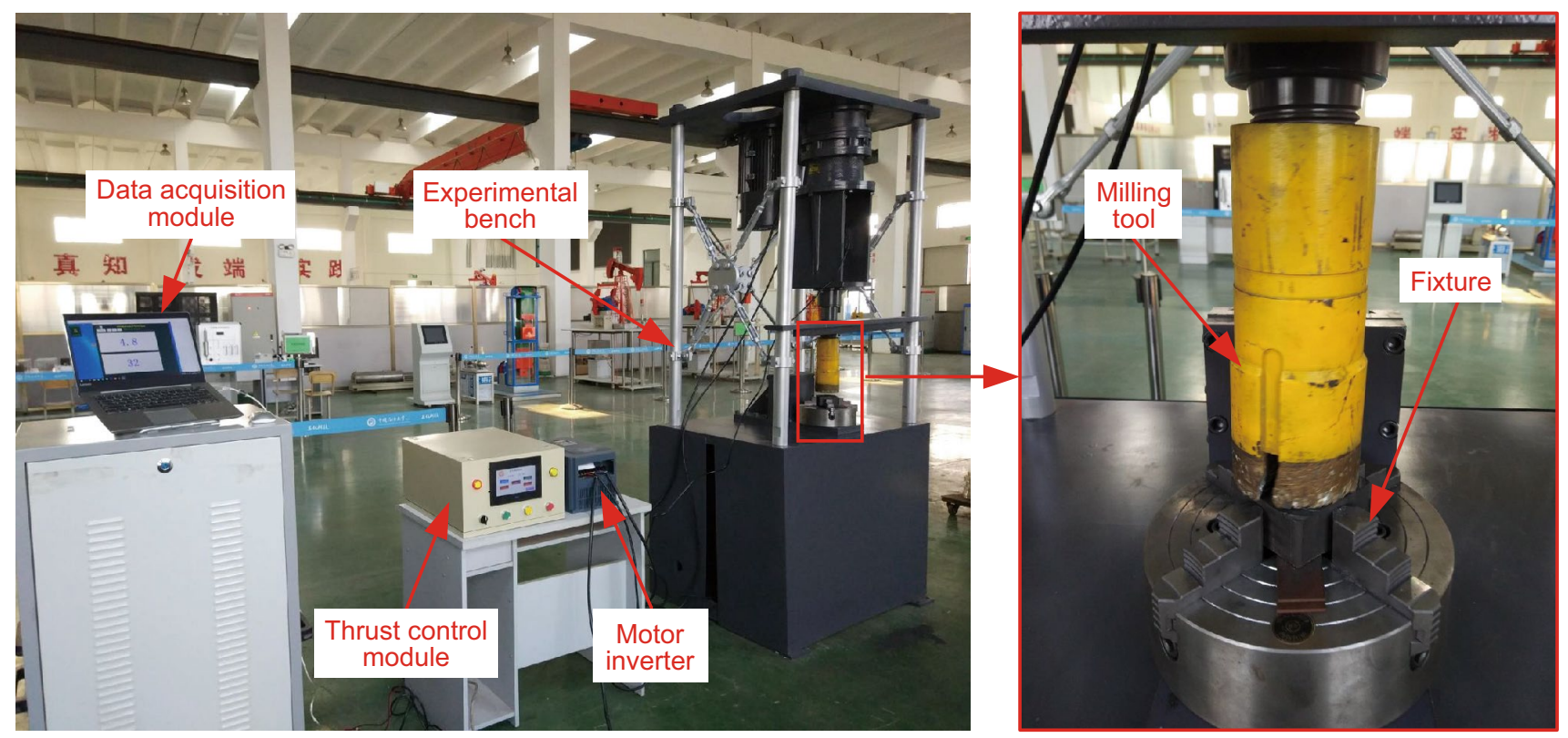

Fig. 3 Experimental system for milling tools

M400 data acquisition management software. The torque sensor, rotating speed sensor, and pressure sensor are used to measure the torque, rotating speed, and the WOB data during the milling process in real time. The software of M400 data acquisition management collects instrument measurement data through a computer serial port and it can display the data in real time. At the same time, it can draw corresponding curves and export data to meet different needs.

\section{(2) Different milling tools}

According to the construction records of well 74-1HF in Shengli Oilfield and considering the types of milling tools commonly used to mill multistage fracturing ball seats of the Sinopec Shengli Oilfield Company's Petroleum Engineering Technology Research Institute, three types of milling tools, including the flat milling tool, the blade milling tool, and the slope milling tool, were selected to be tested by the experimental system for milling tools. Besides, the working performance of the milling tools was evaluated from three perspectives of working efficiency, working safety, and wear resistance, which was helpful to guide on-site construction. For easy installation and comparison, the nominal outside diameter of the experimental milling tool is $100 \mathrm{~mm}$, and the joint threads are both NC26. The structure of three different milling tools is shown in Fig. 4. Among them, the end surface of the flat milling tool is mainly formed by irregular cemented carbide abrasive grains. The whole end surface is relatively flat and there is no obvious cutting edge, which makes the working efficiency quite low. The end surface of the blade milling tool is made of three blades. The blades superimposed by irregular cemented carbide abrasive grains form three complete cutting edges on the end surface of the blade milling tool along the direction of rotation. The end surface of the slope milling tool has a slope structure, and the slope milling tool has three inclined cutting edges along the direction of rotation.

\section{(3) Material of multistage fracturing ball seat}

As the multistage fracturing ball seat in the wellbore is faced with large pressure of fracturing fluid and erosion from fracturing sands, multistage fracturing ball seats are usually made of wear-resistant materials. The chemical composition analysis of the multistage fracturing ball seat provided by Shengli Oilfield was performed, and the chemical composition of multistage fracturing ball seats is shown in Table 1.

At the same time, the mechanical properties of the multistage fracturing ball seat provided by Shengli Oilfield were tested, and the mechanical performance parameters of multistage fracturing ball seats are shown in Table 2. After that, the microstructure of the multistage fracturing ball seat was observed and the microstructure of the multistage fracturing ball seat was obtained as shown in Fig. 5. Through the observation and evaluation of microstructure, it can be seen that the main component of the multistage fracturing ball seat is ferrite, of which the white part is ferrite and the black part is spherical graphite. Besides, it also contains a small amount of pearlite. To be more specific, the graphite grade is 1-3 and the graphite length is grade 6-7, from which it can be known that it is a kind of ferritic nodular cast 

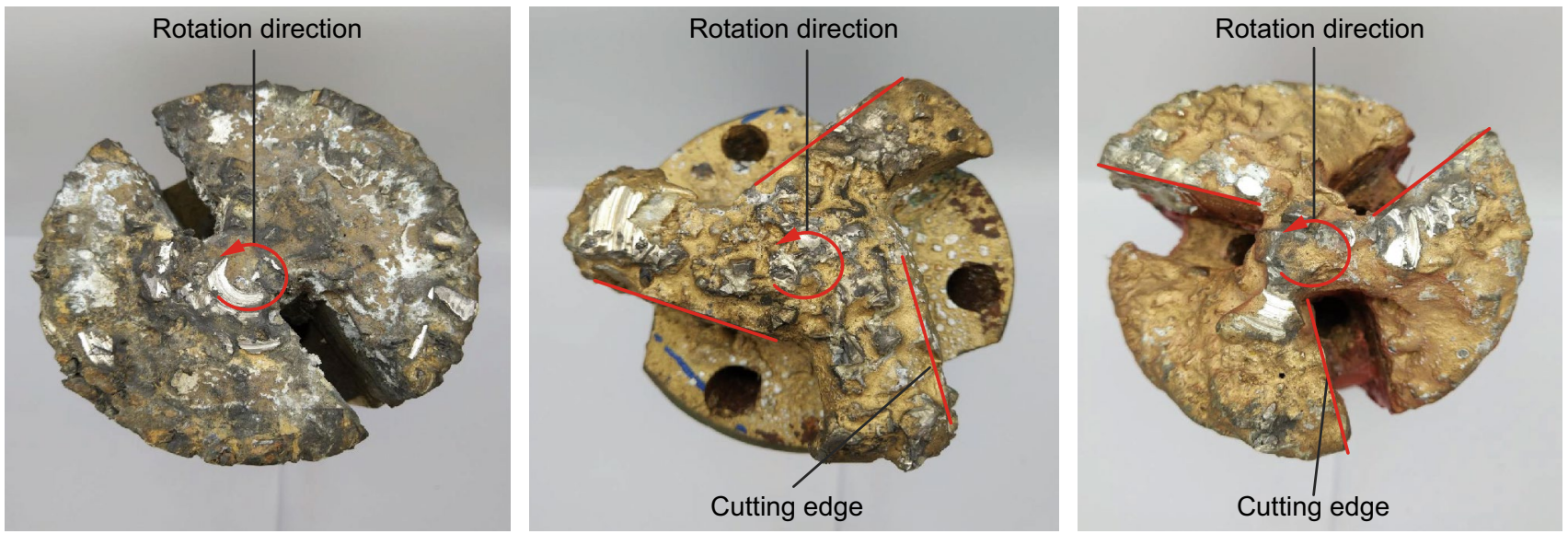

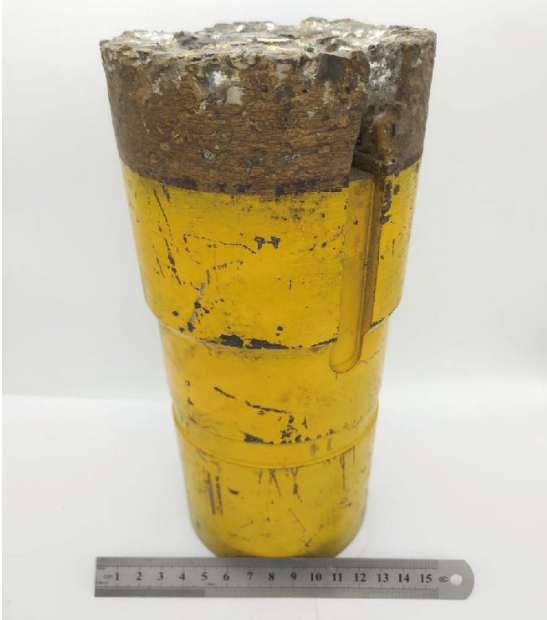

(a) Flat milling tool



(b) Blade milling tool

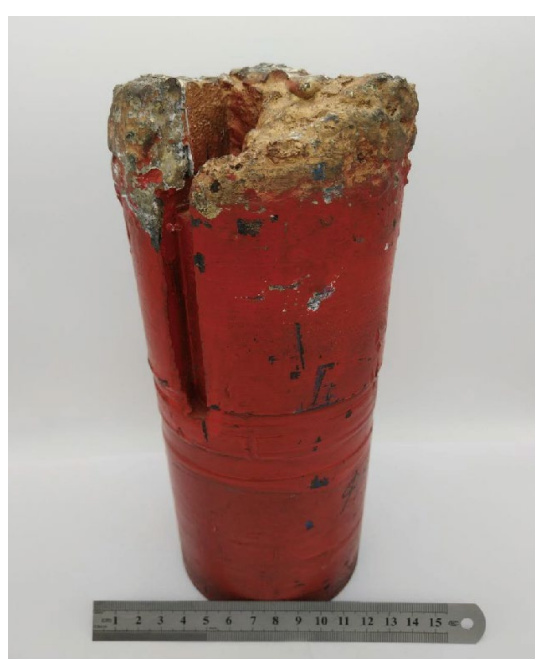

(c) Slope milling tool

Fig. 4 Structure of different milling tools

Table 1 Chemical composition of multistage fracturing ball seats

\begin{tabular}{llllll}
\hline $\mathrm{C}, \%$ & $\mathrm{Si}, \%$ & $\mathrm{Mn}, \%$ & $\mathrm{P}, \%$ & $\mathrm{~S}$, & $\mathrm{Mg}, \%$ \\
\hline 3.35 & 2.55 & 0.31 & 0.040 & 0.011 & 0.035
\end{tabular}

Table 2 Mechanical performance parameters of multistage fracturing ball seats

\begin{tabular}{lll}
\hline Material properties & Unit & Value \\
\hline Tensile strength & $\mathrm{MPa}$ & 510 \\
Elongation & $\%$ & 7 \\
Hardness & $\mathrm{HB}$ & $170-190$ \\
Yield strength & $\mathrm{MPa}$ & 500 \\
Elastic modulus & $\mathrm{GPa}$ & 173 \\
Poisson's ratio & - & 0.30 \\
Density & $\mathrm{kg} / \mathrm{m}^{3}$ & 7300 \\
\hline
\end{tabular}

iron. Comprehensively consider the chemical composition, mechanical performance parameters, and microstructure of the multistage fracturing ball seat, it can be sure that the material of the multistage fracturing ball seat is QT500-7. So, QT500-7 was selected as the material of experimental workpiece for the performance test of different milling tools.

\subsection{Experimental process}

Through the analysis above, QT500-7, as the same material of the multistage fracturing ball seat, was selected as the experimental workpiece. Then, three common milling tools including the flat milling tool, the blade milling tool, and the slope milling tool were tested by the experimental system for milling tools. The specific experimental process was as follows. 


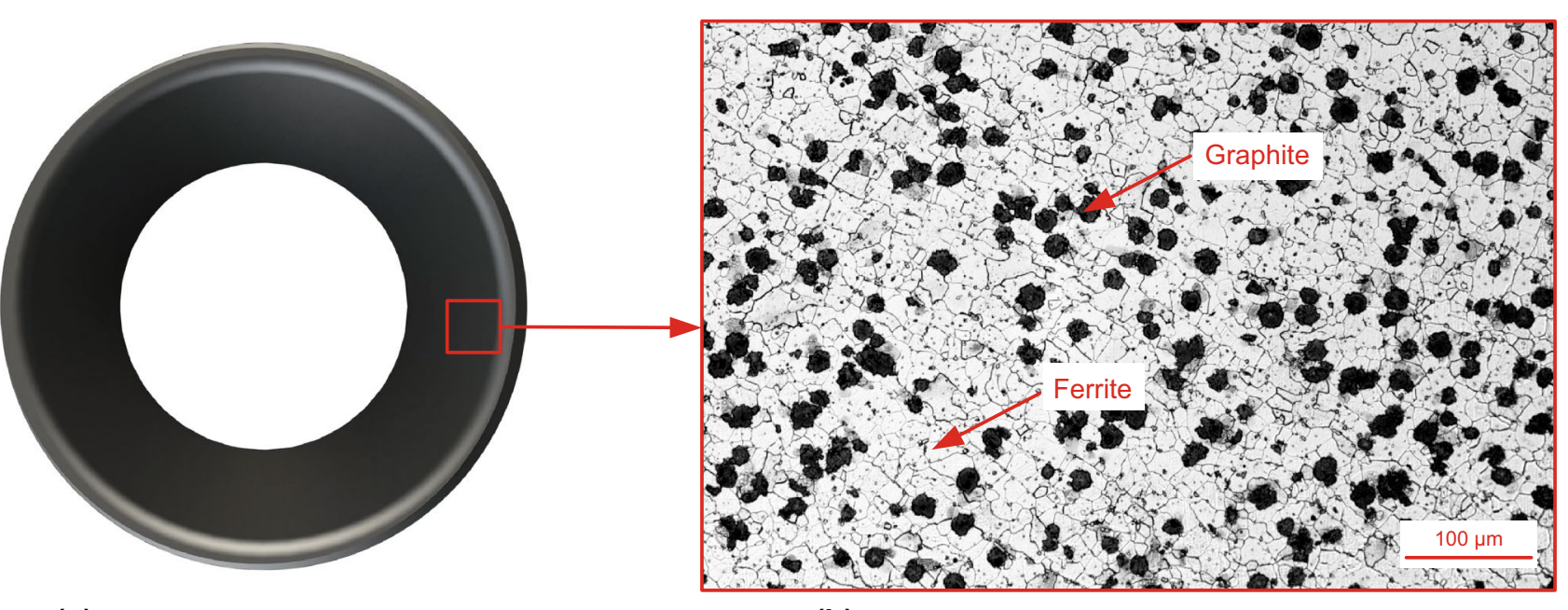

(a) Multistage fracturing ball seat

(b) Microstructure of multistage fracturing ball seat

Fig. 5 Microstructure of the multistage fracturing ball seat

\section{(1) Start the experimental system for milling tools}

When the experimental system was started, to begin with, the experimental workpiece was clamped by the four-jaw chuck and the power switch of the variable frequency motor was turned on. Then, the variable frequency motor started to rotate and the rotating speed was adjusted by the frequency conversion module to simulate the impact of the rotating speed on the milling process. Besides, according to the set thrust, the electric cylinder pushed the experimental platform to move upward along the guide rail. When the experimental workpiece contacted the milling tool, the pressure sensor started to show real-time pressure. According to the value of the pressure sensor, the thrust control module adjusted the thrust through feedback adjustment system, so that the output thrust of the electric cylinder was consistent with the set one to simulate the impact of WOB on the milling process. At this time, the data acquisition module recorded the rotating speed, torque, and pressure to conduct the experimental study of the working performance for different milling tools.

\section{(2) Close the experimental system for milling tools}

When the experimental system is closed, the "return to origin" button in the motor thrust control module is first turned. At this time, the thrust motor rotates in the reverse direction, and the thrust cylinder of the thrust motor is retracted to the initial position, thereby driving the table to move down the guide rail to Limit position, then turn off the power switch of the frequency conversion motor, at this time the frequency conversion motor stops rotating, and finally remove the milling sample to complete the experimental test of the working performance of the milling tool.
(3) Replace different milling tools

When changing different milling tools, first of all, the experimental system for milling tools was closed, and the milling tool for this experiment was removed. Then, the next milling tool and the threaded joint were connected with a threaded connection, and a new experimental workpiece was replaced at the same time. After that, the experimental system for milling tools was started to complete the experiment of working performance for different milling tools. According to the above steps, the experiment of working performance was completed for three commonly used milling tools including the flat milling tool, the blade milling tool, and the slope milling tool in order. The working parameters of each milling tool were the same, including the experimental WOB of $5 \mathrm{kN}$, the rotating speed of $60 \mathrm{r} / \mathrm{min}$, and the milling time of $5 \mathrm{~min}$. In order to ensure the reliability of the experimental results, five sets of repeated experiments from $1 \#$ to $5 \#$ of each milling tool were conducted under the same working condition parameters.

\subsection{Processing experimental results}

(1) Record the working torque of the milling tool

During the experiment of milling tools, the torque sensor in the experimental system could record the working torque of the milling tool in real time, and the data collection was completed through the M400 data acquisition management software. And the working torque could be displayed in real time. Meanwhile, corresponding curves could be drawn and the data could be exported to facilitate the analysis of experimental results in the later period. 


\section{(2) Record the remove mass of workpieces}

The material of workpieces was the same as that of the multistage fracturing ball seat. To facilitate clamping and experimental test, the experimental workpiece was uniformly processed into a rectangular parallelepiped structure of $100 \times 100 \times 50 \mathrm{~mm}$. At the same time, the mass of the workpiece before and after the experiment was weighed by the electronic balance. The mass of the experimental workpiece before and after the experiment is shown in Fig. 6. The model of electronic balance was METTLER TOLEDO ME2002E. And the readability was $0.01 \mathrm{~g}$, the diameter of the weighing pan was $90 \mathrm{~mm}$, and the interface was RS232, which met the precision requirement for the mass change of the experimental workpiece.

\section{(3) Record the wear mass of milling tool}

Relying on the experimental system for milling tools, the experiments of three types of milling tools, including the flat milling tool, the blade milling tool, and the slope milling tool, were conducted. Also, the quality of the milling tool before and after each experiment was recorded through the electronic balance. So, the wear quality of the milling tool could be determined according to the quality change of the milling tool in each experiment, which was used as an evaluation index of the wear resistance of the milling tool.
(3) Analysis of the surface morphology

In order to quantitatively analyze and evaluate the surface of the workpiece after the experiment, the surface morphology of the workpiece after the experiment was obtained through the ultra-clear microscopic imaging system, and a 3D model of the surface morphology of the workpiece was constructed at the same time. The intelligent measurement mode was used to accurately measure the surface shape of the workpiece after the experiment. The model of the ultra-clear microscopic imaging system was LY-WN-YH 3D SYSTEM. This system could image different heights of the sample to obtain plane pictures, and used the superposition of plane pictures to build a 3D model as the surface morphology of the workpiece after the experiment. The intelligent measurement mode accurately measured the three-dimensional space. The structure of the ultra-clear microscopic imaging system is shown in Fig. 7.

\section{Results and discussion}

\subsection{Morphology analysis of chips}

The material QT500-7 of multistage fracturing ball seats was milled by the experimental system for milling tools, and the morphology and microstructure of the chips from the experimental workpiece was analyzed. As a result, the morphology and microstructure of the chips from the

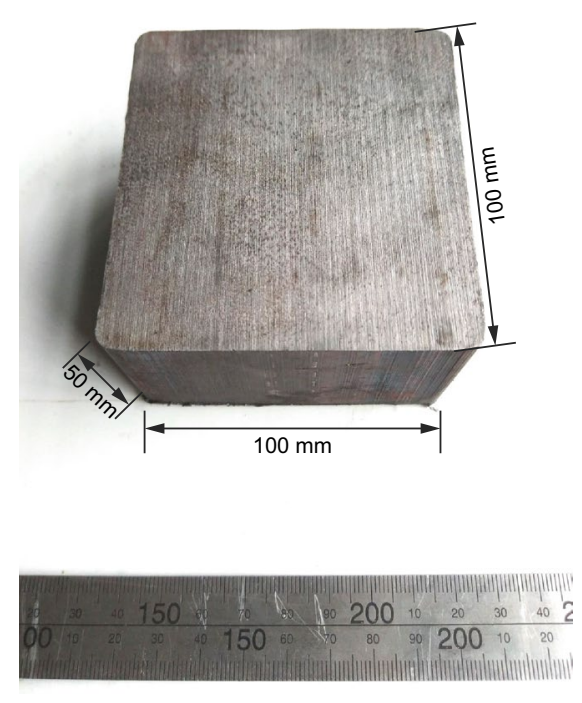

(a) Experimental workpiece



(b) Mass before experiment

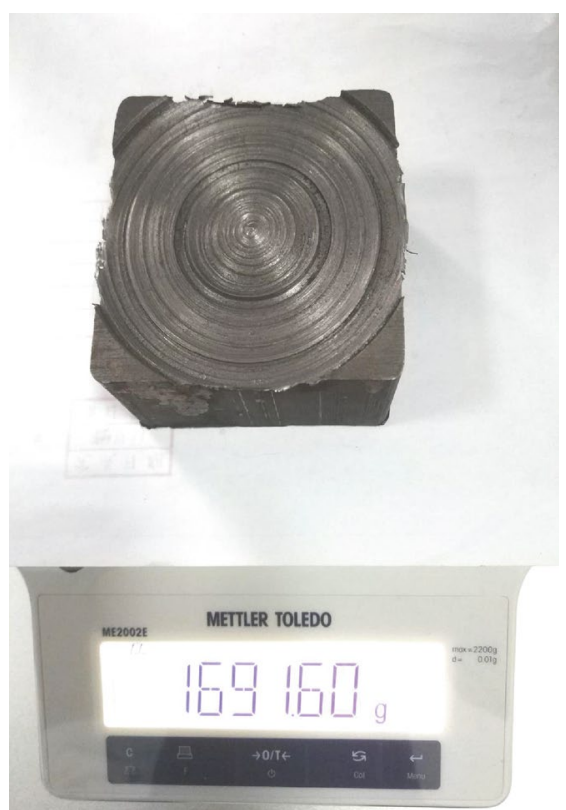

(c) Mass after experiment

Fig. 6 Mass of workpiece before and after the experiment 


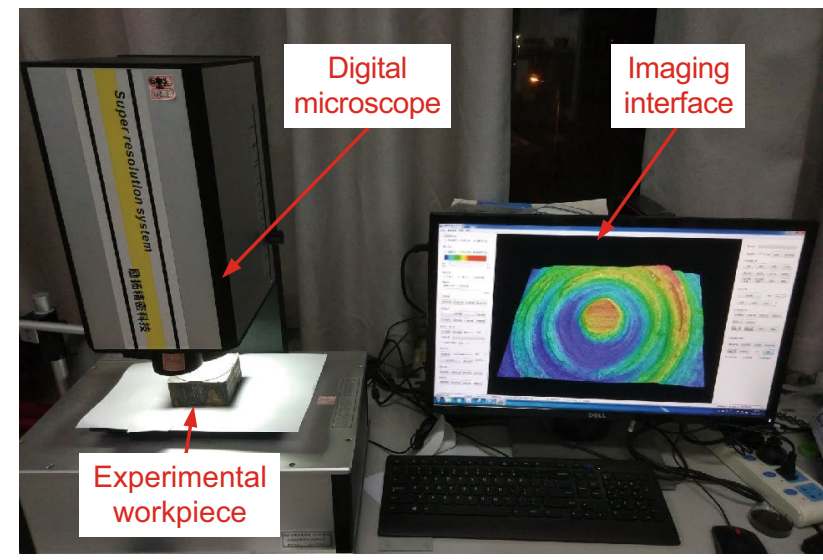

Fig. 7 Ultra-clear microscopic imaging system

experimental workpiece are shown in Fig. 8. As the morphology and microstructure of the chips obtained by different milling tools in the five sets of repeated experiments from $1 \#$ to $5 \#$ were consistent basically, the morphology and microstructure of the chips were mainly related to the material of the workpiece. From the morphology of the chips after the experiment as shown in Fig. 8a, chips of the experimental workpiece are mainly fine powder with relatively uniform grain size. It can be seen from the microstructure of the chips in Fig. 8b that the chips are irregular grains and the grain size is mainly between $10 \mu \mathrm{m}$ and $50 \mu \mathrm{m}$. Milling the material of multistage fracturing ball seats produces a large number of chips with small volume when compared with milling other junks in oil wells. Therefore, the chips of multistage fracturing ball seats should be pumped up to ground at the field construction site of well servicing with a small pump pressure and a large displacement.

\subsection{Surface topography analysis}

As shown in Fig. 9, the surface morphology of the workpiece after the experiment was acquired by an ultra-clear microscopic imaging system, and then the surface morphology of the milled surface on the workpiece was analyzed.

The workpiece after the experiment is shown in Fig. 9a, from where it can be seen that there are some annular cuts on the surface of the workpiece after the experiment and the cuts at different positions have different cutting depths. It shows that these abrasive grains of the milling tool are not on the same plane, which results in different stress conditions of each abrasive grain and different cutting depths. Also, from the microstructure of the workpiece shown in Fig. 9b, after the experiment, a cylinder appears in the center of the workpiece surface and the diameter of the cylinder is about $2 \mathrm{~mm}$. That is to say, a zero point of cutting speed occurs in the work process of the milling tool, which causes the material at that position to remain uncut condition. As a result, the cylinder at the center of the workpiece will become a support point that prevents the milling tool from milling downward and ultimately affects the working efficiency of the milling tool. To better analyze the influence of the cylinder at the center of the workpiece, the surface topography of the central pivot was obtained through an ultra-clear microscopic imaging system and combined with 3D imaging technology. The surface topography image of the workpiece in the area was obtained as shown in Fig. 9c. The image can accurately measure the depth of cuts at different positions through the intelligent measurement mode,

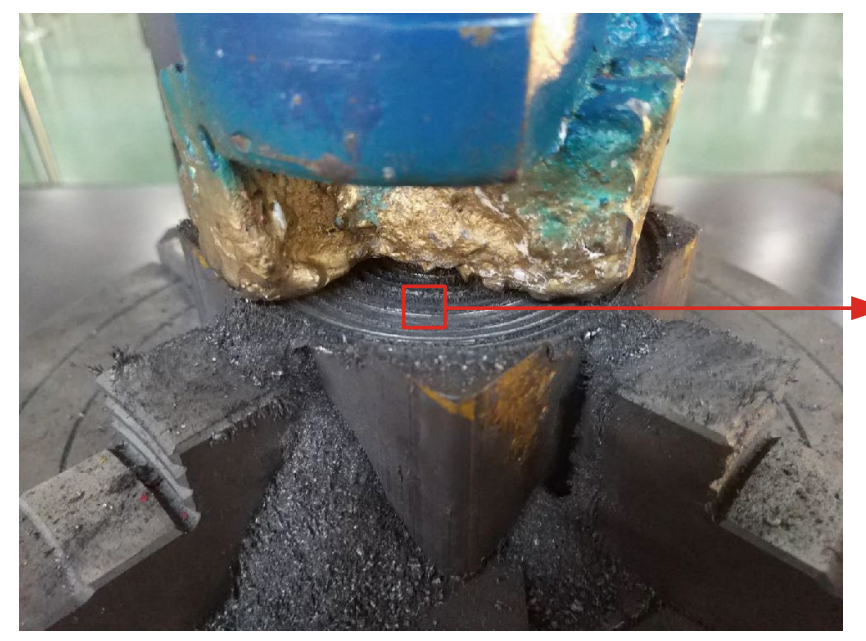

(a) Chips after experiment

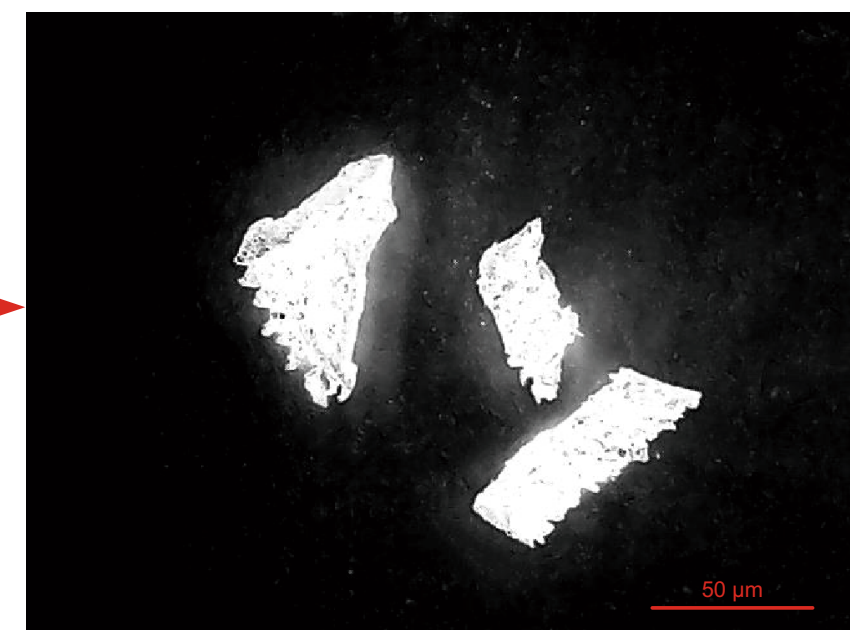

(b) Microstructure of chips

Fig. 8 Chip morphology and microstructure 


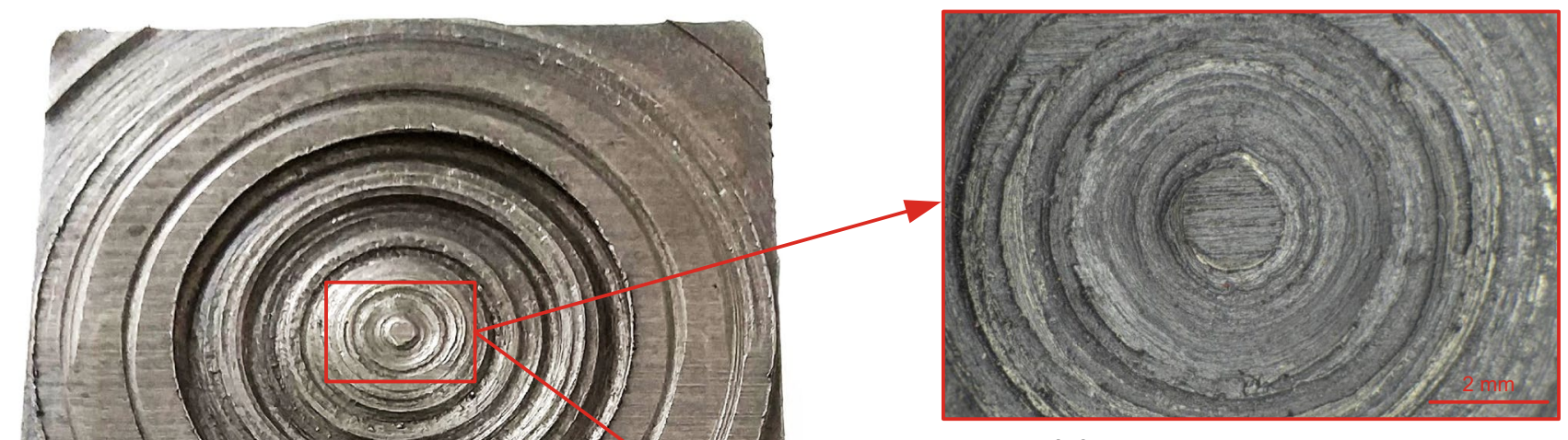

(b) Microstructure of workpiece

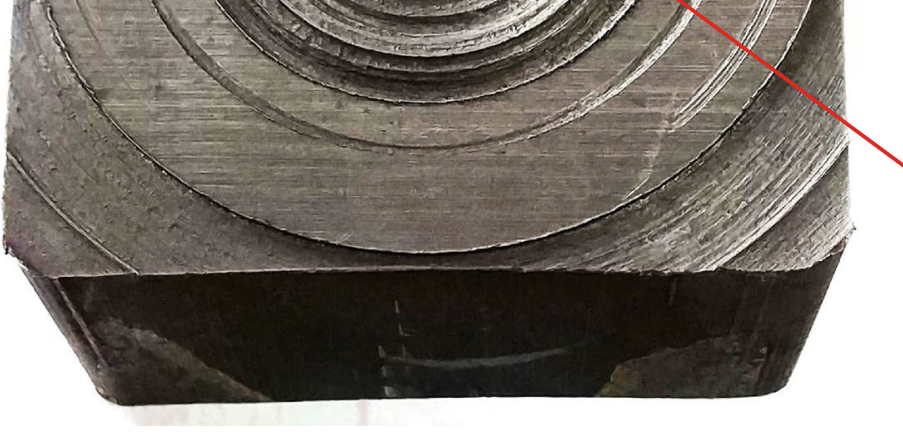

(a) Workpiece after experiment

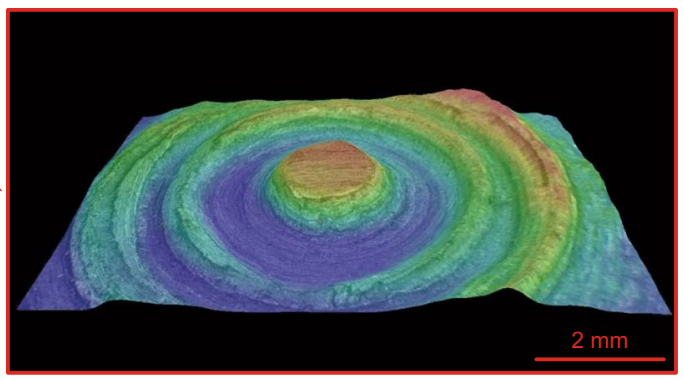

(c) Surface appearance of workpiece

Fig. 9 Surface morphology of the workpiece after the experiment

which is convenient for the quantitative analysis and evaluation of the surface morphology of the milled surface from the workpiece after the experiment. And at the same time, the impact of the central pivot at the center of the workpiece surface was analyzed.

The experimental results show that the surface contours of the workpieces obtained by the same milling tool in five sets of repeated experiments from $1 \#$ to $5 \#$ were basically the same, but the surface contours of central pivots formed by different milling tools were different, indicating that the surface morphology of the workpiece was related to the type of the milling tool. Then, the workpiece surface topography image in Fig. 9c was cut through the center position, and the surface contours of the central pivots formed by different milling tools are shown in Fig. 10. Among them, the surface contour of the central pivot formed by the flat milling tool is shown in Fig. 10a. It can be seen from Fig. 10a that the center position of the workpiece surface is not involved in the cutting process, so it has the highest height. The outer diameter of the center cylinder is $2120.97 \mu \mathrm{m}$, the cutting depth on the left is $224.65 \mu \mathrm{m}$, and the figure on the right is $216.20 \mu \mathrm{m}$. The cutting depths on the two sides are inconsistent because the workpiece was not fully leveled when clamping the workpiece. According to the previous mechanical analysis model of single abrasive grain, the torque of the milling tool will fluctuate with the fluctuation of the abrasive grain cutting depth. The surface contour of the central pivot formed by the blade milling tool is shown in Fig. 10b. The outer diameter of the center cylinder is $1938.12 \mu \mathrm{m}$, the cutting depth on the left is $551.61 \mu \mathrm{m}$, and the figure on the right is $635.47 \mu \mathrm{m}$. The surface contour of the central pivot formed by the slope milling tool is shown in Fig. 10c. The outer diameter of the center cylinder is $1782.34 \mu \mathrm{m}$, the cutting depth on the left is $323.30 \mu \mathrm{m}$, and the figure on the right is $428.06 \mu \mathrm{m}$.

In general, all three kinds of milling tools produce central pivots, but the central pivot formed by the flat milling tool has the largest outer diameter while that formed by the blade milling tool has the highest height. As the abrasive grains on the bottom surface of the milling tool are not on the same plane, and the structure and shape of abrasive grains are not the same, the cutting depth of each abrasive grain is not consistent, which affects the working efficiency of milling tools. Therefore, the carbide abrasive grains on the same cutting edge of the milling tool should be arranged as evenly as possible. Besides, during the working process of the milling tool, the uncut cylinder at the center of the workpiece surface will become a support point that preventing the milling tool from milling downward and ultimately affecting the working efficiency of milling tools. So, an eccentric structure is needed on the bottom surface of milling tools to avoid the zero point of cutting speed that affects work efficiency. 

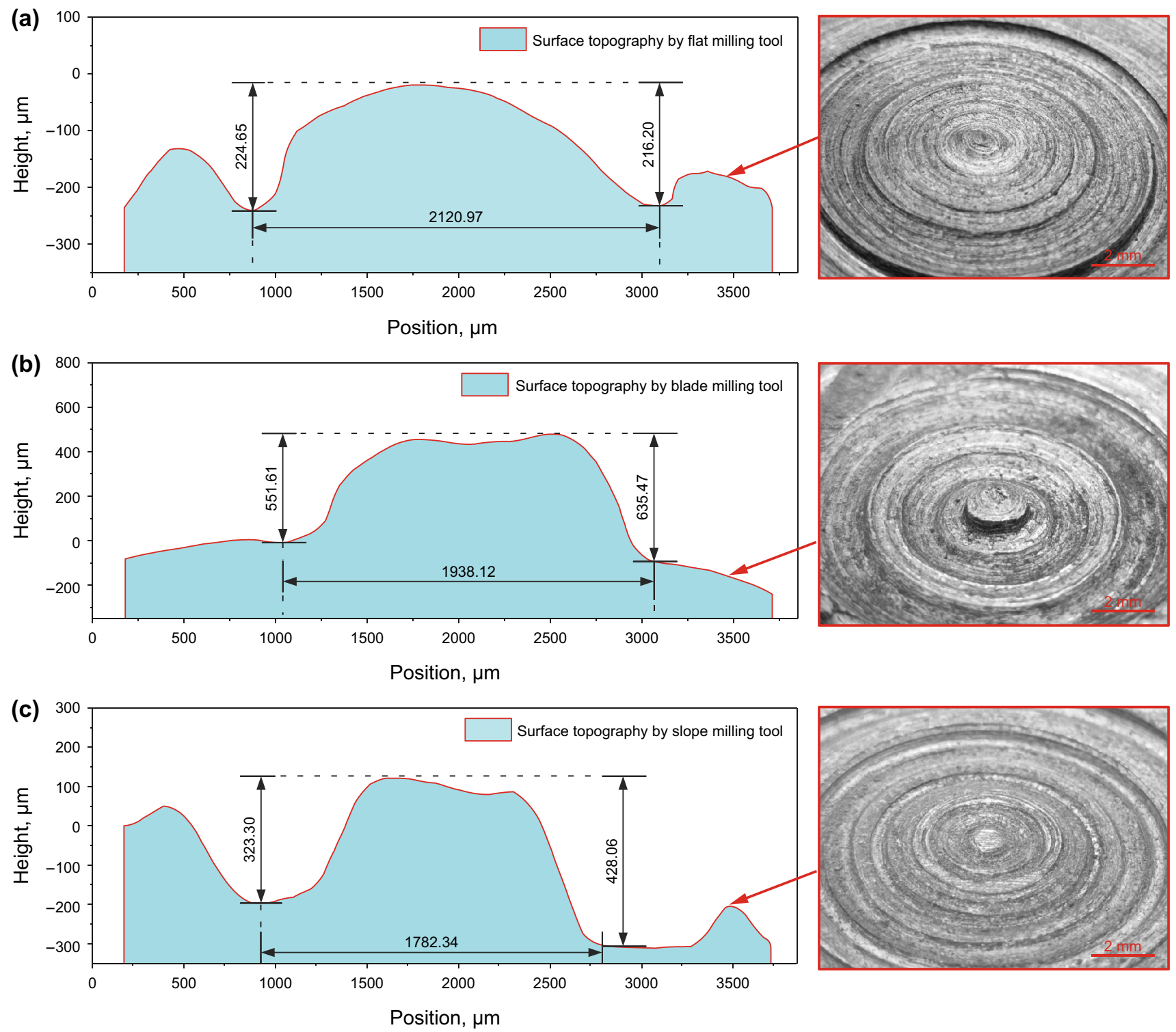

Fig. 10 Surface contours of the central pivots formed by different milling tools

\subsection{Working safety evaluation}

Since the magnitude and fluctuation of the working torque directly affect the construction safety of the pipe string for servicing, the working torque is used as the evaluation index of the working safety of milling tools. The experimental results show that the torque curves of the same milling tool in the five sets of repeated experiments from $1 \#$ to $5 \#$ are basically the same, while those of different milling tools are different. So, the average torque of the same milling tool in the five sets of repeated experiments from $1 \#$ to $5 \#$ was calculated to show the torque curve of this kind of the milling tool. As a result, the working torque curves of different milling tools are shown in Fig. 11a, and the average value and standard deviation of working torque in the stable fluctuation range of different milling tools are shown in Fig. 11b. In general, it can be seen from Fig. 11a that the working torque curves of the three milling tools increase rapidly at first and then become stable gradually in the end. This is due to the effect of WOB; the abrasive grains on the bottom surface of the milling tool gradually press into the surface of the workpiece. At the same time, the cutting depth $h$ and cutting width $b$ of the abrasive grains gradually increase. According to the analysis results obtained from the previous mechanical analysis model of single abrasive grain, the torque of the milling tool increases nonlinearly with the increase in cutting depth $h$ of the abrasive grain and increases linearly with the increase in cutting width $b$. 

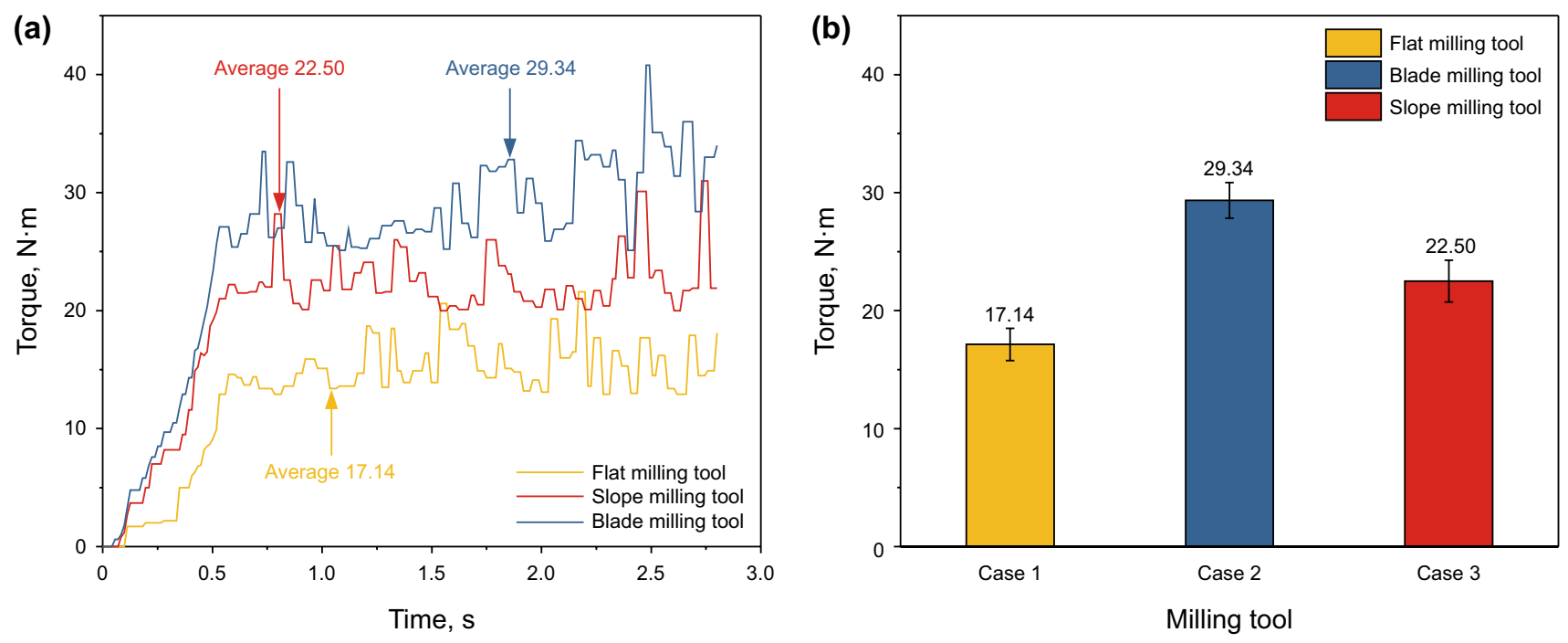

Fig. 11 Working torque of different milling tools

So, the torque of the milling tool increases rapidly at the beginning. As the abrasive grains are further pressed into the surface of the workpiece, the resistance to the abrasive grains, including the resistance from the elastic and plastic deformation of the workpiece and the friction of the contact section, also increases roughly, which preventing the abrasive grains continue to be pressed into the surface of the workpiece. At the same time, the cutting depth $h$ and cutting width $b$ of the abrasive grains stop increase, so the torque of the milling tool gradually stabilizes in the later stage.

Specifically, when the flat milling tool starts to rotate, the torque of the flat milling tool increases rapidly at first and reaches $13.23 \mathrm{~N} \mathrm{~m}$ at $0.5 \mathrm{~s}$ and then enters a stable milling state from 0.5 to $3.0 \mathrm{~s}$. The stable fluctuation range of working torque is $12.93-21.56 \mathrm{~N} \mathrm{~m}$, and the average value of working torque in the stable fluctuation range is $17.14 \mathrm{~N} \mathrm{~m}$ with a standard deviation of $1.37 \mathrm{~N} \mathrm{~m}$. The bottom surface of the flat milling tool is made of irregular cemented carbide abrasive grains by welding, and the overall surface is relatively flat without a complete cutting edge. So, the cutting depth $h$ and the cutting width $b$ are relatively small, which results in the fact that the working torque of the flat milling tool is very small and stable.

When the blade milling tool starts to rotate, the working torque of the blade milling tool increases rapidly and reaches $25.65 \mathrm{~N} \mathrm{~m}$ at $0.5 \mathrm{~s}$ and then enters a stable milling state at the time of $0.5-3.0 \mathrm{~s}$. The stable fluctuation range of working torque is $25.11-40.13 \mathrm{~N} \mathrm{~m}$, and the average value of working torque in the stable fluctuation range is $29.34 \mathrm{~N}$ m with a standard deviation of $1.50 \mathrm{~N}$ $\mathrm{m}$. Because the bottom surface of the blade milling tool has three blades and these blades are made of irregular cemented carbide abrasive grains by welding and the three edges of the three blades form three relatively complete cutting edges, the cutting depth $h$ and the cutting width $b$ are relatively large. Therefore, the working torque of the blade milling tool is considerably large. But the three cutting edges made of irregular cemented carbide abrasive grains are not regular enough, which makes the working process of the blade milling tool very unstable. So, its fluctuation range of the working torque is relatively large, which affects the construction safety.

When the slope milling tool starts to rotate, the torque of the slope milling tool increases rapidly at first and reaches $21.25 \mathrm{~N} \mathrm{~m}$ at $0.5 \mathrm{~s}$ and then enters a stable milling state at the period of $0.5-3.0 \mathrm{~s}$. The working torque is generally stable and the fluctuation range is $20.02-30.92 \mathrm{~N} \mathrm{~m}$, and the average of value working torque in the stable fluctuation range is $22.50 \mathrm{~N}$ m with a standard deviation of $1.76 \mathrm{~N}$ $\mathrm{m}$. The bottom surface of the slope milling tool is a slope structure and the front end surface of the slope structure is made of regular cemented carbide abrasive grains. The side edges of the front end surface on the slope form three complete cutting edges, so the cutting depth $h$ and the cutting width $b$ are relatively large. Therefore, compared with the flat milling tool, the working torque of the slope milling tool is larger. And because the three cutting edges are made of regular cemented carbide abrasive grains, the working process of the slope milling tool is relatively stable. Therefore, compared with the blade milling tool, both the average value and fluctuation range of the working torque of the slope milling tool are small.

In general, in the process of cutting the material from the multistage fracturing ball seat, the working torque of the slope milling tool is $23.8 \%$ larger than that of the flat milling tool and $30.4 \%$ smaller than that of the blade milling tool. 
The working torque fluctuation range of the slope milling tool is $20.8 \%$ larger than that of the flat milling tool and $37.8 \%$ smaller than that of the blade milling tool. Therefore, the slope milling tool has the characteristics of moderate torque and stable working conditions, which can better ensure the safety of oil field construction.

\subsection{Working efficiency evaluation}

Since the remove mass of the workpiece under the same time and the same working condition parameters can reflect the working efficiency of the milling tool, the remove mass of the workpiece is used as the evaluation index of the working efficiency of the milling tool, and the remove mass of workpieces by different milling tools is shown in Fig. 12. Among them, the five sets of repeated experiments from 1\# to $5 \#$ on different milling tools were carried out. As a result, the remove mass of workpieces by different milling tools in the five sets of repeated experiments from $1 \#$ to $5 \#$ is shown in Fig. 12a, and the average value and variation range of the remove mass of different milling tools are shown in Fig. 12b. It can be seen from Fig. 12a that in the five sets of repeated experiments from $1 \#$ to $5 \#$, the remove mass of the slope milling tool is generally greater than that of the blade milling tool, and the remove mass of the blade milling tool is generally larger than that of the flat milling tool. Figure $12 \mathrm{~b}$ shows that as the most commonly used milling tool for milling multistage fracturing ball seats in the Shengli Oilfield, the average remove mass of the flat milling tool is only $101.87 \mathrm{~g}$, and the change range of that is from 95.56 to $105.67 \mathrm{~g}$, so the fluctuation range of the remove mass is within $6.2 \%$. The average remove mass of the blade milling tool is $183.24 \mathrm{~g}$, and the change range of that is between 172.33 and $192.87 \mathrm{~g}$,

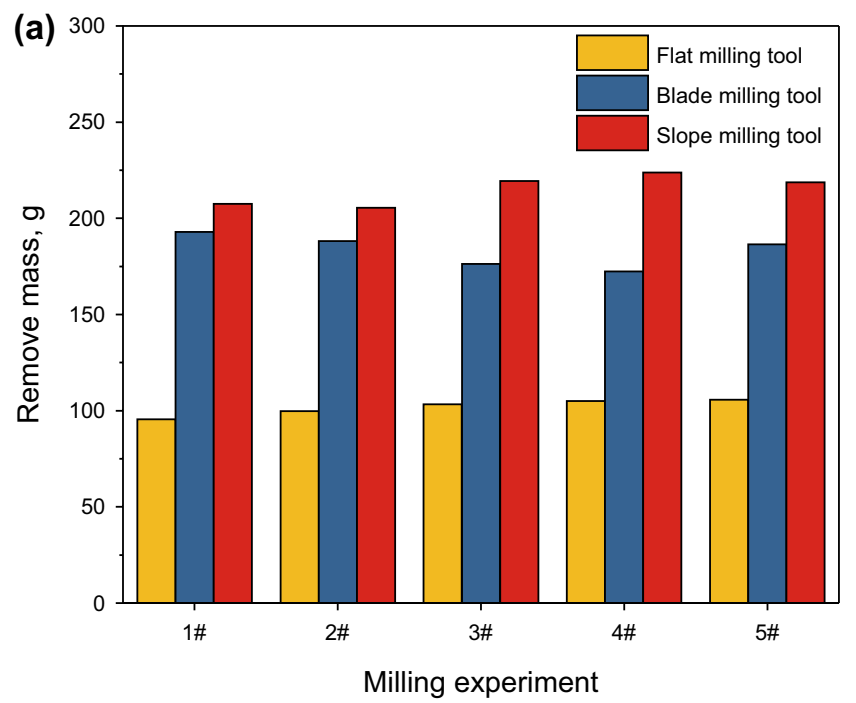

so the fluctuation range of the remove mass is within $6.0 \%$. Compared with the flat milling tool, the working efficiency of the blade milling tool improves by $79.9 \%$. The average remove mass of the slope milling tool is $215.01 \mathrm{~g}$, and the change range of that is between $205.49 \mathrm{~g}$ and $223.84 \mathrm{~g}$, so the fluctuation range of the remove mass is within $4.1 \%$. Compared with the flat milling tool, the working efficiency improves by $111.1 \%$, and the figure improves by $17.3 \%$ when compared with the blade milling tool. It can be seen that the slope milling tool has the highest efficiency in the process of milling multistage fracturing ball seats.

Based on the analysis results of working efficiency, the structural characteristics of different milling tools are further analyzed as follows. Among them, the end surface of the flat milling tool is mainly formed by irregular cemented carbide abrasive grains. The whole end surface is relatively flat and there is no obvious cutting edge, which makes the working efficiency quite low. The end surface of the blade milling tool is made of three blades. The blades superimposed by irregular cemented carbide abrasive grains form three complete cutting edges on the end surface of the blade milling tool along the direction of rotation. Similarly, the cutting edge plays an essential part in the process of cutting the material on multistage fracturing ball seats, so the blade milling tool improves the working efficiency by $79.9 \%$ when compared to the flat milling tool.

The end surface of the slope milling tool has a slope structure and the specific structure is shown in Fig. 13. Along the direction of rotation, the front end surface of the slope structure is made of regular cylindrical carbide abrasive grains by welding, and the other parts are made of irregular cemented carbide abrasive grains by welding. Therefore, three complete cutting edges are formed by regular cylindrical carbide

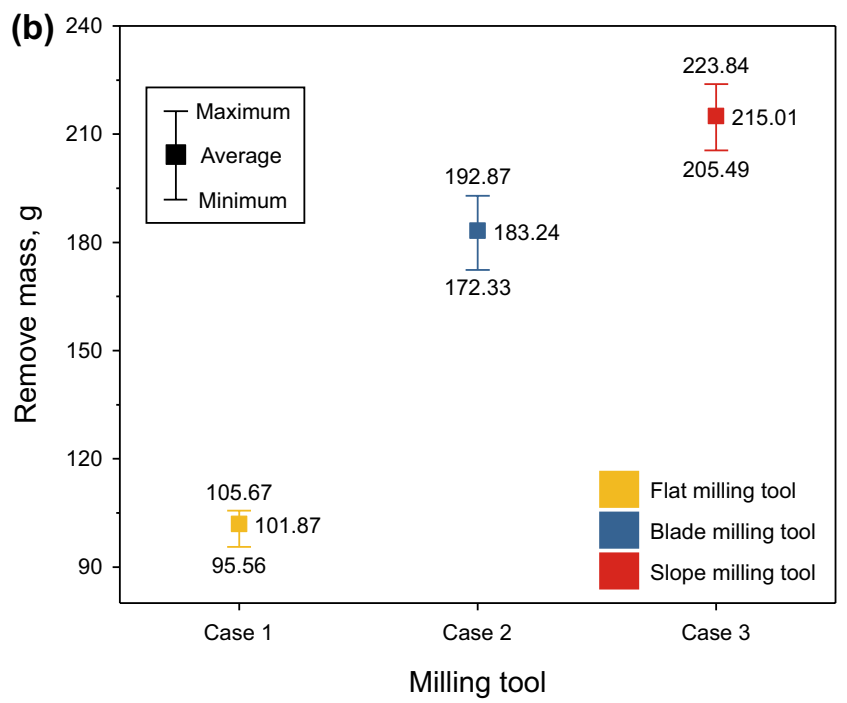

Fig. 12 Remove mass of workpieces by different milling tools 


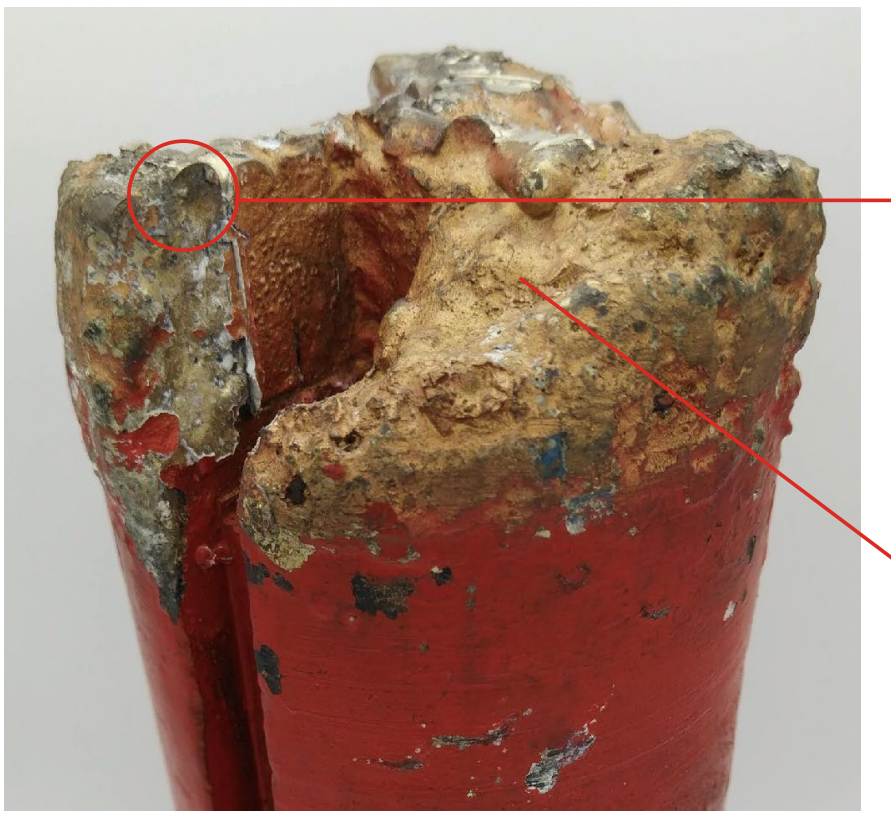

(a) Slope milling tool

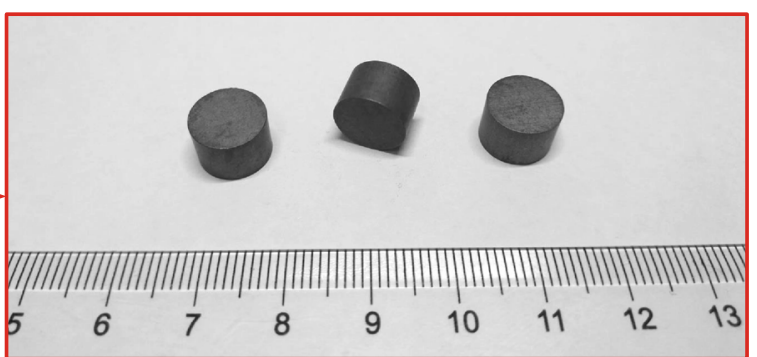

(b) Cemented carbide abrasive grains

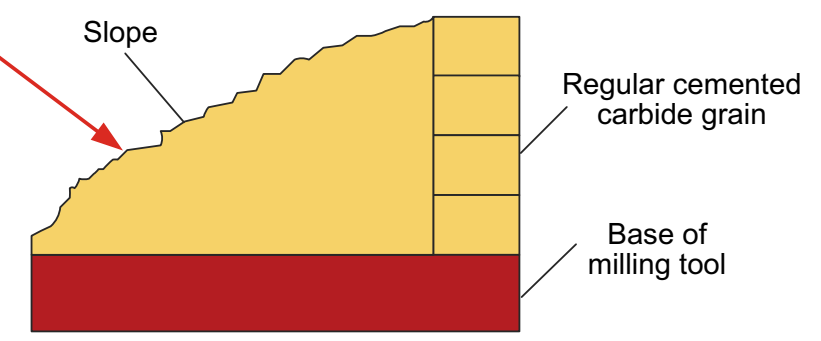

(c) Slope structure

Fig. 13 Structural characteristic of the slope milling tool

abrasive grains, which play a major role in the process of milling. So, when compared with the flat milling tool, the working efficiency of the slope milling tool improves by $111.1 \%$. Besides, the cutting edges of the blade milling tool are horizontally arranged while the cutting edges of the slope milling tool are inclined. This kind of slope structure with inclined cutting edges is more suitable for milling the material of multistage fracturing ball seats. Therefore, compared with the blade milling tool, the working efficiency of the slope milling tool improves by $17.3 \%$.

The working process of the slope milling tool is further analyzed below, and the working process of the slope milling tool is shown in Fig. 14.

The working process of the slope milling tool can be divided into the following four stages. In the first stage, the regular abrasive grain at the front end surface of the slope structure plays the main role of cutting. The material of multistage fracturing ball seats is cut by the regular abrasive grain rapidly. At this moment, the working efficiency of the slope milling tool is the highest. In the second stage, the regular abrasive grain at the front end surface of the slope structure begins to appear some failure phenomena such as damage, gully, and crack, leading to the result that the cutting edge of the regular abrasive grain is incomplete. As a result, the working efficiency of the slope milling tool decreases gradually. In the third stage, the weld between the abrasive grain and the substrate fails, resulting in the fact that the regular abrasive grain at the front end surface of the slope structure falls off from the slope milling tool.
Therefore, the irregular abrasive grain at the rear end surface of the slope structure is used to complete the process of cutting. Because the irregular abrasive grain does not have a complete cutting edge, the working efficiency of the slope milling tool is the lowest at this time. In the fourth stage, with the wear of the irregular abrasive grain at the rear end surface of the slope structure, the regular abrasive grain at the front end surface of the slope structure gradually comes into contact with the material of the multistage fracturing ball seat and completes the process of cutting. At this moment, the working efficiency of the slope milling tool recovers to the highest, and a new cycle starts at this point. Therefore, the slope milling tool with slope structure and multiple layer structure of regular abrasive grains can give full play to the efficient cutting performance of regular abrasive grains. As the regular abrasive grain falls off in time after failure and the regular abrasive grain on the next layer starts the process of efficient cutting quickly, the slope milling tool has a higher working efficiency in a longer period.

\subsection{Wear resistance of milling tools}

Because the wear mass of the milling tool under the same time and same working condition parameters can reflect the wear resistance of the milling tool, and the wear resistance directly affects the service life of the milling tool, the wear mass of the milling tool is used as the evaluation index of wear resistance, and the wear mass of different milling tools is shown in Fig. 15. 


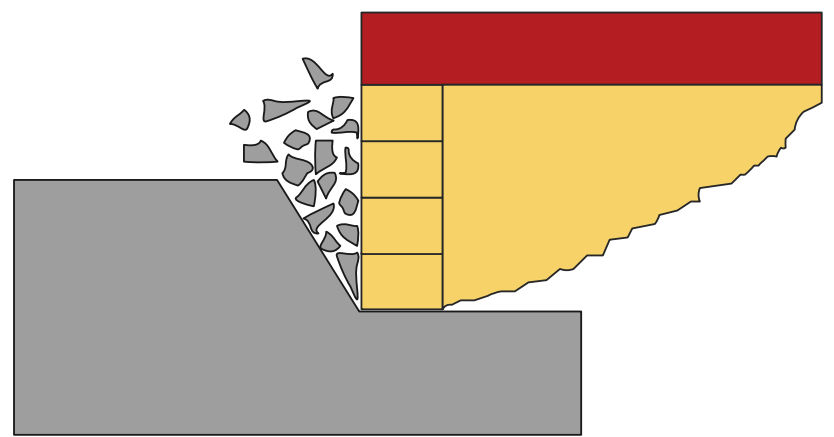

(a) Abrasive grain works

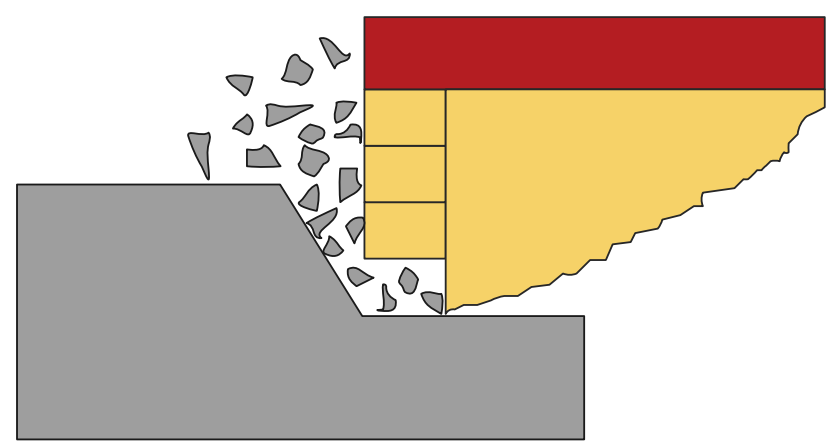

(c) Abrasive grain falls off

Fig. 14 Working process of the slope milling tool

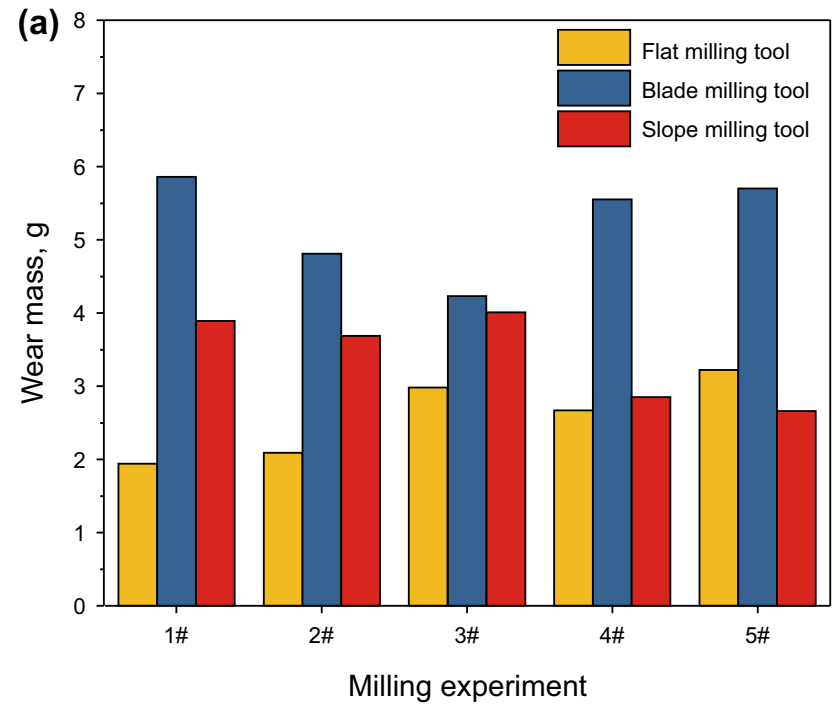

Fig. 15 Wear mass of different milling tools

Then, the five sets of repeated experiments from 1\# to $5 \#$ on different milling tools were carried out. As a result, the wear mass of different milling tools in the five sets of repeated experiments from 1\# to 5\# is shown in Fig. 15a, and the average value and variation range of the wear mass of different milling tools are shown in Fig. 15b. It can be

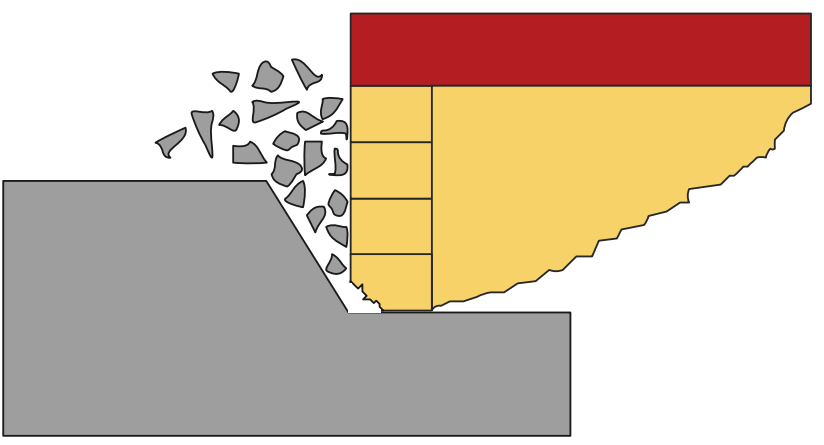

(b) Abrasive grain fails

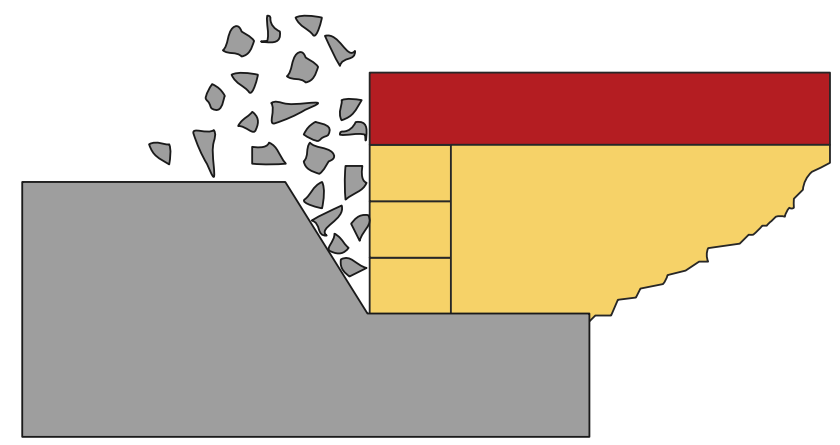

(d) Next abrasive grain works

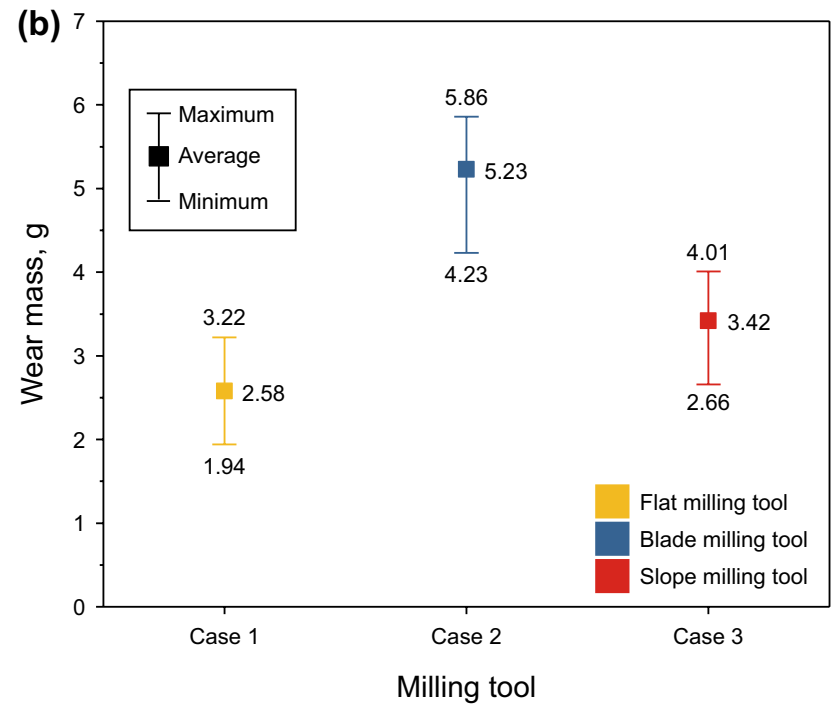

seen from Fig. 15a that in the five sets of repeated experiments from 1\# to 5\#, the wear mass of the flat milling tool is generally lower than that of the slope milling tool and the wear mass of the slope milling tool is generally lower than that of the blade milling tool. Besides, Fig. 15b shows that the average wear mass of the flat milling tool is only 
$2.58 \mathrm{~g}$, and the change range of that is from 1.94 to $3.22 \mathrm{~g}$, so the fluctuation range of the wear mass is within $24.8 \%$. The average wear mass of the blade milling tool is $5.23 \mathrm{~g}$, and the change range of that is between 4.23 and $5.86 \mathrm{~g}$, so the fluctuation range of the wear mass is within $19.1 \%$. The wear resistance of the blade milling tool decreases by $102.7 \%$ when compared with the flat milling tool. The average wear mass of the slope milling tool is $3.42 \mathrm{~g}$, and the change range of that is between 2.66 and $4.01 \mathrm{~g}$, so the fluctuation range of the wear mass is within $22.2 \%$. Compared with the flat milling tool, the wear resistance declines by $32.6 \%$, and the figure improves by $34.6 \%$ when compared with the blade milling tool.

It can be seen that in the process of milling the material of the multistage fracturing ball seat, the wear resistance of the flat milling tool is the best while that of the blade milling tool is the worst. The wear resistance of the slope milling tool is fine, which is close to the flat milling tool. This is because the contact area of the flat milling tool with the workpiece is large, and the stress of a single abrasive grain is relatively small, so the flat milling tool has the best wear resistance. Besides, the cutting edge of the slope milling tool is formed of regular cylindrical carbide abrasive grains by welding, and the abrasive grains are relatively uniformly stressed, so the wear resistance of the slope milling tool is better than that of the blade milling tool.

\section{Conclusions}

This paper mainly studies the working performance of different milling tools for milling multistage fracturing ball seats. Firstly, the working mechanism of milling tools for multistage fracturing ball seats was studied and a mechanical analysis model of single abrasive grain was established. Then, an experimental system for milling tools was developed, and the experimental tests of three commonly used milling tools including the flat milling tool, the blade milling tool, and the slope milling tool were completed in order under the same working conditions. After that, the morphology of chips and the surface morphology of the workpiece after the experiment were analyzed to determine the working mechanism of the milling tool. Finally, the working performance of different milling tools was evaluated from the perspectives of working safety, working efficiency, and wear resistance, which provides a theoretical basis and guidance for milling multistage fracturing ball seats on-site. This is of great significance for removing wellbore blockages and achieving more production at the later stage of multistage fracturing wells. Specifically, the following conclusions were obtained.
(1) From the mechanical analysis model of single abrasive grain, it can be known that the torque of the milling tool increases nonlinearly with the increase in the cutting depth of the carbide abrasive grain, and increases linearly with the increase in the cutting width. Also, the change of front angle of the abrasive grain leads to periodic fluctuations.

(2) The result from the morphology analysis of chips shows that the chips produced by the milling tool to remove the material of multistage fracturing ball seats are mainly fine powder with relatively uniform grain size. Chips are irregular grains on the microcosmic scale, and the grain size is mainly between $10 \mu \mathrm{m}$ and $50 \mu \mathrm{m}$. Compared with milling other tools in oil wells, milling the material of multistage fracturing ball seats produces a large number of chips with small volume. Therefore, the chips of multistage fracturing ball seats should be pumped up to ground at the field construction site of well servicing with a small pump pressure and a large displacement.

(3) The result of surface topography analysis shows that there are some annular cuts on the surface of the workpiece after the experiment and the cuts at different positions have different cutting depths. The cutting depth at the analysis position varies from 216.20 to $635.47 \mu \mathrm{m}$. Besides, a cylinder appears in the center of the workpiece surface. All three kinds of milling tools produce central pivots. The outer diameter of the central pivot formed by the flat milling tool is the largest that can reach $2120.97 \mu \mathrm{m}$, while the height of the central pivot formed by the blade milling tool is the highest that can reach $635.47 \mu \mathrm{m}$. During the working process of the milling tool, the uncut cylinder at the center of the workpiece surface will become a support point that preventing the milling tool from milling downward and ultimately affecting the working efficiency of milling tools. So, the bottom surface of the milling tool should be eccentric to avoid the zero point of cutting speed that affects work efficiency.

(4) Under the working conditions that the WOB of the milling tool is $5 \mathrm{kN}$, the rotating speed is $60 \mathrm{r} / \mathrm{min}$, the milling time is $5 \mathrm{~min}$, and the workpiece is the material of multistage fracturing ball seats; it can be known that the working torque of the slope milling tool is $23.8 \%$ larger than that of the flat milling tool and $30.4 \%$ smaller than that of the blade milling tool. The working torque fluctuation range of the slope milling tool is $20.8 \%$ larger than that of the flat milling tool and $37.8 \%$ smaller than that of the blade milling tool. Besides, the remove mass of the workpiece by the flat milling tool is only $101.87 \mathrm{~g}$. When compared with the flat milling tool, the working efficiency of the blade milling tool improves by $79.9 \%$ and the slope milling 
tool improves by $111.1 \%$. The wear mass of the flat milling tool is $2.58 \mathrm{~g}$. Compared with the flat milling tool, the wear resistance of the blade milling tool drops by $102.7 \%$, and that of the slope milling tool falls by $32.6 \%$. Therefore, the slope milling tool has the characteristics of moderate torque, stable working conditions, the highest working efficiency, and fine wear resistance that is close to the flat milling tool, which is preferably used to mill multistage fracturing ball seats.

\begin{abstract}
Acknowledgements This work was supported by the National Science and Technology Major Project under Grant Nos. 2016ZX05042004 and 2017ZX05072, the Joint Funds of the National Natural Science Foundation of China under Grant No. U1762104, the Postgraduate Innovation Project Foundation under Grant No. YCX2019054, the Fundamental Research Funds for the Central Universities under Grant No. 20CX02306A, and the Opening Fund of National Engineering Laboratory of Offshore Geophysical and Exploration Equipment. Also, we thank the Shengli Oilfield and the Sinopec Petroleum Engineering Technology Research Institute for providing experimental materials and field data.
\end{abstract}

Open Access This article is licensed under a Creative Commons Attribution 4.0 International License, which permits use, sharing, adaptation, distribution and reproduction in any medium or format, as long as you give appropriate credit to the original author(s) and the source, provide a link to the Creative Commons licence, and indicate if changes were made. The images or other third party material in this article are included in the article's Creative Commons licence, unless indicated otherwise in a credit line to the material. If material is not included in the article's Creative Commons licence and your intended use is not permitted by statutory regulation or exceeds the permitted use, you will need to obtain permission directly from the copyright holder. To view a copy of this licence, visit http://creativecommons.org/licenses/by/4.0/.

\section{References}

Ajibose OK, Wiercigroch M, Akisanya AR. Experimental studies of the resultant contact forces in drillbit-rock interaction. Int J Mech Sci. 2015;91:3-11. https://doi.org/10.1016/j.ijmecsci.2014.10.007.

Cai L, Xiao G, Lu S, et al. Spatial-temporal coupling between highquality source rocks and reservoirs for tight sandstone oil and gas accumulations in the Songliao Basin, China. Int J Min Sci Technol. 2019;29(3):387-97. https://doi.org/10.1016/j.ijmst .2019.03.006.

Che D, Zhu WL, Ehmann KF. Chipping and crushing mechanisms in orthogonal rock cutting. Int J Mech Sci. 2016;119:224-36. https ://doi.org/10.1016/j.ijmecsci.2016.10.020.

Che D, Zhang W, Ehmann K. Chip formation and force responses in linear rock cutting: an experimental study. J Manuf Sci Eng. 2017;139(1):011011. https://doi.org/10.1115/1.4033905.

Chen P, Meng M, Miska S, et al. Study on integrated effect of PDC double cutters. J Pet Sci Eng. 2019a;178:1128-42. https://doi. org/10.1016/j.petrol.2019.04.024.

Chen P, Meng M, Ren R, et al. Modeling of PDC single cutter-Poroelastic effects in rock cutting process. J Pet Sci Eng. 2019b;183:106389. https://doi.org/10.1016/j.petrol.2019.106389.

Cheng W, Jiang GS, Xie JY, et al. A simulation study comparing the Texas two-step and the multistage consecutive fracturing method.
Pet Sci. 2019a;16(5):1121-33. https://doi.org/10.1007/s1218 2-019-0323-9.

Cheng Z, Li G, Huang Z, et al. Analytical modelling of rock cutting force and failure surface in linear cutting test by single PDC cutter. J Pet Sci Eng. 2019b;177:306-16. https://doi.org/10.1016/j. petrol.2018.09.023.

Hashiba K, Fukui K, Liang YZ, et al. Force-penetration curves of a button bit generated during impact penetration into rock. Int J Impact Eng. 2015;85:45-56. https://doi.org/10.1016/j.ijimp eng.2015.06.007.

Hu J, Zhang C, Rui Z, et al. Fractured horizontal well productivity prediction in tight oil reservoirs. J Pet Sci Eng. 2017;151:159-68. https://doi.org/10.1016/j.petrol.2016.12.037.

Kivade SB, Murthy CSN, Vardhan H. Experimental investigations on penetration rate of percussive drill. Procedia Earth Planet Sci. 2015;11:89-99. https://doi.org/10.1016/j.proeps.2015.06.012.

Li S, Zhang D, Li X. A new approach to the modeling of hydraulic fracturing treatments in naturally fractured reservoirs. SPE J. 2017;22(4):1064-81. https://doi.org/10.2118/181828-MS.

Li J, Li XR, Zhan HB, et al. Modified method for fracability evaluation of tight sandstones based on interval transit time. Pet Sci. 2019a. https://doi.org/10.1007/s12182-019-00397-x.

Li L, Tan J, Wood DA, et al. A review of the current status of induced seismicity monitoring for hydraulic fracturing in unconventional tight oil and gas reservoirs. Fuel. 2019b;242:195-210. https://doi. org/10.1016/j.fuel.2019.01.026.

Liu Z, Wang Z, Ren G, et al. Researching and testing on casing ball seat for multistage fracturing in horizontal wells. Int Pet Technol Conf. 2020. https://doi.org/10.2523/IPTC-19612-MS.

Lundberg B, Collet P. Optimal wave shape with respect to efficiency in percussive drilling with detachable drill bit. Int J Impact Eng. 2015;86:179-87. https://doi.org/10.1016/j.ijimpeng.2015.06.021.

Miyazaki K, Ohno T, Karasawa H, et al. Performance evaluation of polycrystalline diamond compact percussion bits through laboratory drilling tests. Int J Rock Mech Min Sci. 2016;100(87):1-7. https://doi.org/10.1016/j.ijrmms.2016.04.020.

Munoz H, Taheri A, Chanda E. Rock cutting characteristics on softto-hard rocks under different cutter inclinations. Int J Rock Mech Min Sci. 2016;100(87):85-9. https://doi.org/10.1016/j.ijrmm s.2016.05.014.

Peng X, Zeng T, Yin Z, et al. Experimental study on drilling basalt with small diameter drilling tools. Adv Space Res. 2019;64(5):117787. https://doi.org/10.1016/j.asr.2019.05.038.

Qu HJ, Yang B, Tian XH, et al. The primary controlling parameters of porosity, permeability, and seepage capability of tight gas reservoirs: a case study on Upper Paleozoic Formation in the eastern Ordos Basin, Northern China. Pet Sci. 2019;16(6):1270-84. https ://doi.org/10.1007/s12182-019-00373-5.

Rostamsowlat I. Effect of cutting tool properties and depth of cut in rock cutting: an experimental study. Rock Mech Rock Eng. 2018;51(6):1715-28. https://doi.org/10.1007/s00603-018-1440-2.

Shi HZ, Ji ZS, Zhao HQ, et al. Investigations into the coiled tubing partial underbalanced drilling (CT-PUBD) technique for drilling hard formations. Pet Sci. 2018;15(4):830-40. https://doi.org/10.1007/ s12182-018-0271-9.

Sun LP, Wu SY, Pan G, et al. Analysis of three-dimensional mechanical model of single-tooth orthogonal cutting. Tool Eng. 2018;52(11):118-21 (in Chinese).

Sun LD, Zou CN, Jia AL, et al. Development characteristics and orientation of tight oil and gas in China. Pet Explor Dev. 2019;46(6):1073-87. https://doi.org/10.1016/S1876 -3804(19)60264-8.

Wang M, Chen S, Lin M. Enhancing recovery and sensitivity studies in an unconventional tight gas condensate reservoir. Pet Sci. 2018;15(2):305-18. https://doi.org/10.1007/s12182-018-0220-7. 
Zhang SC, Lei X, Zhou YS, et al. Numerical simulation of hydraulic fracture propagation in tight oil reservoirs by volumetric fracturing. Pet Sci. 2015;12(4):674-82. https://doi.org/10.1007/s1218 2-015-0055-4.

Zhang XS, Wang HJ, Ma F, et al. Classification and characteristics of tight oil plays. Pet Sci. 2016;13(1):18-33. https://doi.org/10.1007/ s12182-015-0075-0.

Zhang Z, Zhao D, Zhao Y, et al. Simulation and experimental study on temperature and stress field of full-sized PDC bits in rock breaking process. J Pet Sci Eng. 2019;186:106679. https://doi. org/10.1016/j.petrol.2019.106679.

Zhao WT, Hou GT. Fracture prediction in the tight-oil reservoirs of the Triassic Yanchang Formation in the Ordos Basin, northern China. Pet Sci. 2017;14(1):1-23. https://doi.org/10.1007/s1218 2-016-0141-2.

Zhao P, Wang Z, Sun Z, et al. Investigation on the pore structure and multifractal characteristics of tight oil reservoirs using NMR measurements: permian Lucaogou Formation in Jimusaer Sag, Junggar Basin. Mar Pet Geol. 2017;86:1067-81. https://doi. org/10.1016/j.marpetgeo.2017.07.011.
Zheng C, Liu Y, Wang H, et al. Research on the effect of gas nitriding treatment on the wear resistance of ball seat used in multistage fracturing. Mater Des. 2015;70:45-52. https://doi.org/10.1016/j. matdes.2014.12.050.

Zheng C, Liu Y, Wang H, et al. Finite element analysis and experimental study on the deformation characteristics of an aluminum alloy fracturing ball. J Nat Gas Sci Eng. 2016a;35:203-10. https://doi. org/10.1016/j.jngse.2016.08.037.

Zheng C, Liu Y, Wang H, et al. Numerical study on the geometry evolution prediction of fracturing tool used for unconventional oil and gas exploitation. Powder Technol. 2016b;303:44-54. https:// doi.org/10.1016/j.powtec.2016.09.007.

Zheng C, Liu Y, Wang H, et al. Numerical study on improving the erosion life of ball seat for oil and gas reservoir fracturing. Eng Fail Anal. 2016c;60:188-98. https://doi.org/10.1016/j.engfailana 1.2015.11.050.

Zou CN, Yang Z, Hou LH, et al. Geological characteristics and "sweet area" evaluation for tight oil. Pet Sci. 2015;12(4):606-17. https:// doi.org/10.1007/s12182-015-0058-1. 